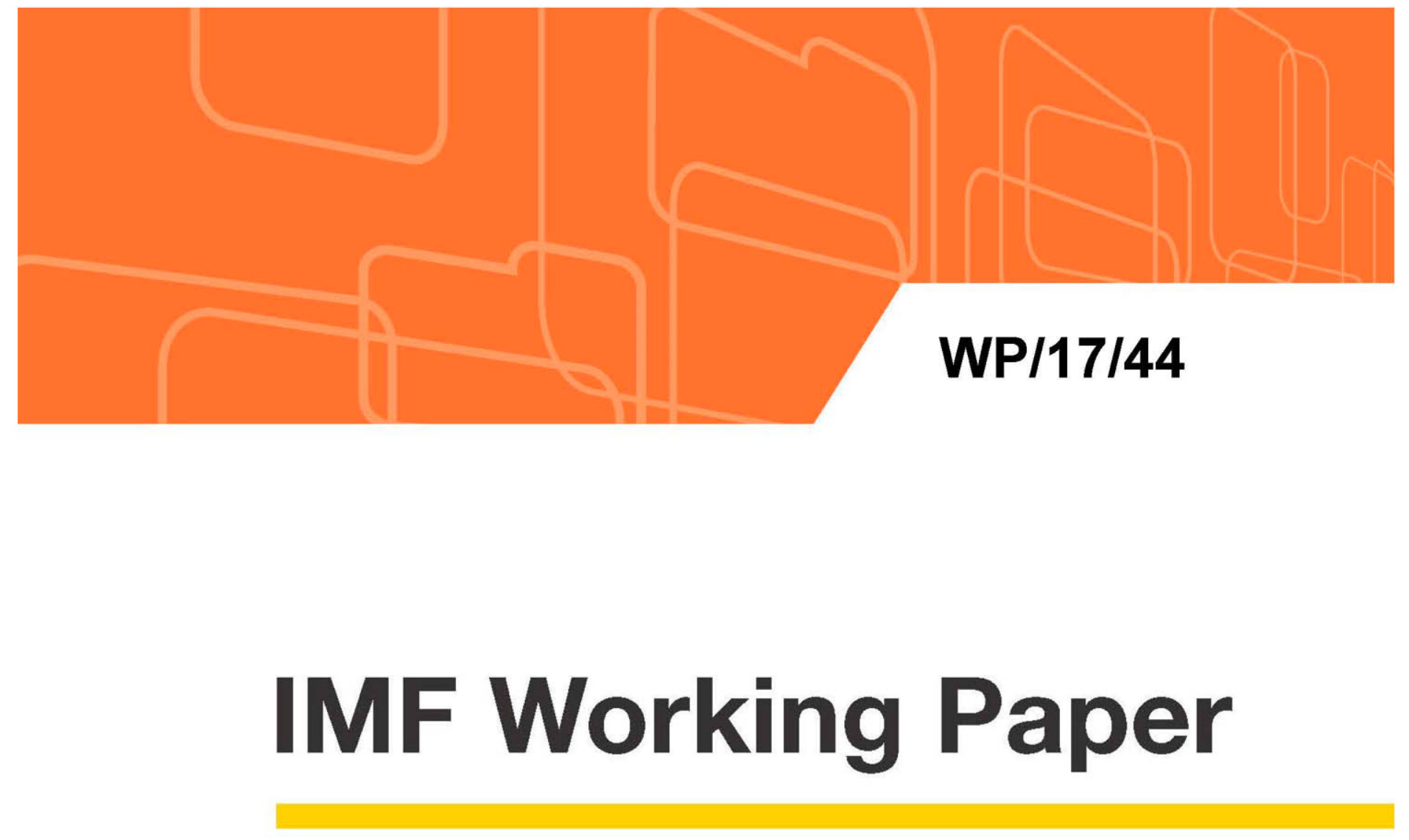

\title{
Effects of Timeliness on the Trade Pattern between Primary and Processed Goods
}

\author{
by Suprabha Baniya
}

IMF Working Papers describe research in progress by the author(s) and are published to elicit comments and to encourage debate. The views expressed in IMF Working Papers are those of the author(s) and do not necessarily represent the views of the IMF, its Executive Board, or IMF management. 


\title{
WP/17/44
}

\section{IMF Working Paper}

\section{Effects of Timeliness on the Trade Pattern between Primary and Processed Goods}

\author{
by Suprabha Baniya
}

IMF Working Papers describe research in progress by the author(s) and are published to elicit comments and to encourage debate. The views expressed in IMF Working Papers are those of the author(s) and do not necessarily represent the views of the IMF, its Executive Board, or IMF management.

I N T E R N A T I O N A L M O N E T A R Y F U N D 


\title{
IMF Working Paper
}

Western Hemisphere Department

\section{Effects of Timeliness on the Trade Pattern between Primary and Processed Goods ${ }^{1}$ Prepared by Suprabha Baniya}

Authorized for distribution by Valerie Cerra

March 2017

\section{IMF Working Papers describe research in progress by the author(s) and are published to elicit comments and to encourage debate. The views expressed in IMF Working Papers are those of the author(s) and do not necessarily represent the views of the IMF, its Executive Board, or IMF management.}

\begin{abstract}
This paper investigates the effect of timeliness in accessing the intermediate inputs on the trade pattern. In particular, any country that has a higher ability to transport goods on time has a comparative advantage in industries that place a higher value on the timely delivery of their inputs, and this comparative advantage pattern is stronger for processed goods than for primary goods. To do this, a measure for how intensively any industry demands for the timely delivery of its intermediate inputs is constructed combining Hummels and Schaur (2013)'s calculations of the time sensitivity of products with the input-output tables.

JEL Classification Numbers: F10, F13, F14, O13, O14, O18

Keywords: Trade, Transportation Infrastructure, Time Sensitivity, Comparative Advantage, Input-Output Linkages, Global Value Chains, Intermediate Inputs, Trade Costs, Logistics

Author's E-Mail Address: SBaniya@purdue.edu

\footnotetext{
${ }^{1}$ Prepared by Suprabha Baniya, a PhD student in the Department of Economics at Purdue University (email: sbaniya@purdue.edu). This paper was prepared as a background study for the Western Hemisphere Department's Cluster Report on Trade Integration in Latin America and the Caribbean.
} 


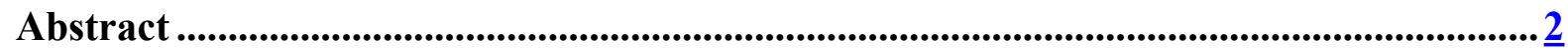

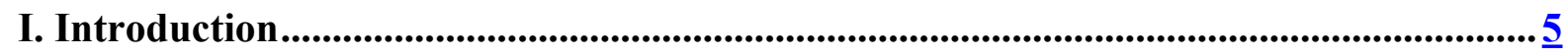

II. Data Sources and Variable Computations.................................................................

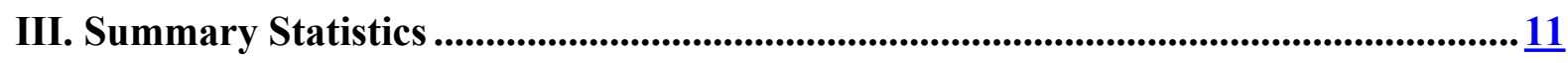

IV. Empirical Framework ................................................................................................... 16

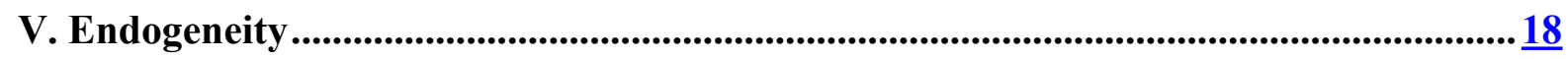

A. Control for Reverse Causality between Trade and Infrastructure ........................ 18

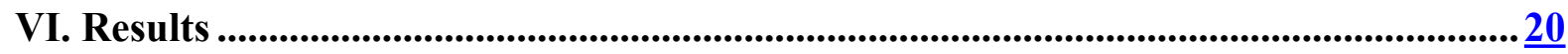

VII. Robustness Check.............................................................................................................. 29

A. Magnification Effects ............................................................................ 29

B. Endogeneity between Upstream and Downstream Production............................. 32

C. Robust Measure for Indirect Time Sensitivity .............................................. $\underline{35}$

D. Dropping the Extraction Sector ............................................................

VIII. Conclusion .................................................................................................................................. $\frac{37}{38}$

IX. Extension to the Firm Heterogeneity CGE Model......................................................... $\underline{38}$

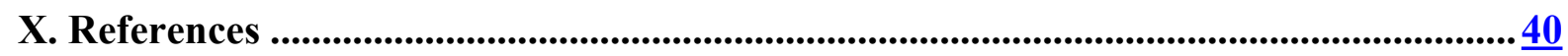

\section{Tables}

1. Measure for Time Sensitivity Across Products ........................................................ 11

2. List of Most Time Sensitive Inputs by their End Use ............................................... 12

3. Effects of Transportation Infrastructure on the Trade Pattern (Baseline) ......................... 20

4. Latin America - LAC (Regression Results with Truncated Sample) .............................. 24

5. Analysis of Results-A Case for Sugar (Numerical Example) ...................................... 25

6a. Effect of a 10\% Improvement in the LPI Level of an Average Country (World)............ 26

6b. Effect of an 8.34\% Improvement in the LPI Level of an Average Country in LAC ........ 27

6c. Effect of an $8.34 \%$ Improvement in the LPI of an Average Country in LAC

(High and Upper Middle Income Countries in Latin America) ........................................ 28

7. Measures of Direct and Indirect Time Sensitivity at the GTAP Sectoral Level ................ $\underline{30}$

8: Control for Magnification Effects ........................................................................ $\underline{33}$

9. Analysis of Results - A Case for Sugar (Numerical Example) ..................................... $\underline{34}$

10. Robust Measure of Indirect Time Intensity ......................................................... $\underline{36}$

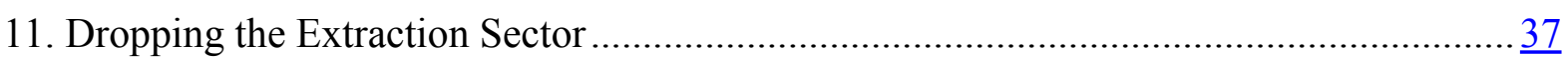




\section{Figures}

1. Direct and Indirect Measures of Time Sensitivity.............................................................

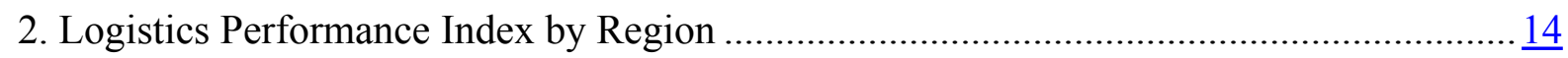

3. Share of Primary Goods in 2013 Total Exports by 2012 Logistics Performance Index ..... 14

4. Share of Processed Goods in 2013 Total Exports by 2012 Logistics Performance ............. 15

5. Country-Specific Weighted Average Upstreamness of Products by LPI............................. 15

6 Country-Specific Weighted Average Indirect Time Sensitivity of Products by LPI …….... $\underline{16}$

7. 2013 Composition of Exports by 2012 Logistics Performance Index (World vs Latin.......22

8a. Effect of a 10\% Improvement in the LPI Level of an Average Country (World).............. 26

8b. Effect of an 8.34\% Improvement in the LPI of Latin America........................................27

8c. Effect of an $8.34 \%$ Improvement in the LPI of Latin America (High and Upper Middle

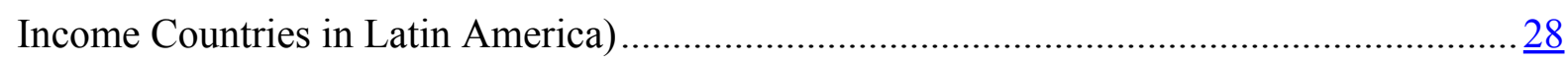

8d. Effect of a 10\% Improvement in the LPI of an Average Country....................................

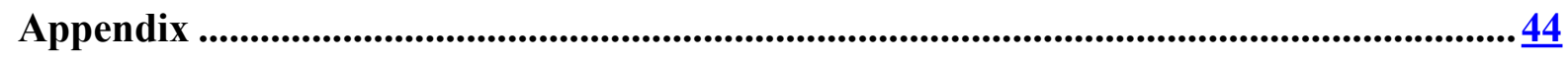




\section{INTRODUCTION $2,3,4,5$}

\section{According to the UNCTAD Handbook of Statistics, more than $\mathbf{7 6}$ percent of total} exports were that of primary commodities for African region, whereas, the figure was less than 19 percent for Asia in 2013. ${ }^{6}$ This paper provides an important explanation for specialization in industries that value timely delivery of inputs - hence the trade pattern between primary and processed goods across countries. In particular, this pattern of trade is explained by introducing the idea of "indirect time costs" of trade arising from input-output linkages: the time costs incurred while accessing the intermediate inputs, after controlling for various confounding factors, significantly determines the trade specialization pattern between primary and processed goods.

2. For this analysis, the indirect time costs of trade across products is computed using the U.S. input-output coefficients, and Hummels and Schaur (2013)'s calculations of the ad-valorem tariff equivalent of consumers' willingness to pay more for a good to be delivered one day earlier. The measure of time sensitivity across products computed in Hummels and Schaur (2013) is denoted in this paper as the "direct time costs" of trade as it provides the consumers' valuation of timely delivery of goods. According to Hummels \& Schaur (2013), time cost of one day in transit is equivalent to an ad-valorem tariff rate of 0.6-2.3 percent. On the other hand, the indirect measure of time sensitivity across products computed in this paper provides producers' valuation of timely delivery of their bundle of intermediate inputs. In particular, this measure for how intensively producers demand for the timely delivery of the bundle of their intermediate inputs is constructed following the procedure

\footnotetext{
${ }^{2}$ I would like to thank my dissertation committee members at Purdue University: Dr. David Hummels, Dr. Thomas Hertel, Dr. Chong Xiang and Dr. Dominique van der Mensbrugghe for their valuable suggestions and comments.

${ }^{3}$ I would also like to thank Dr. Michele Ruta (Lead Economist, World Bank) and Dr. Nadia Rocha (Senior Economist, World Bank) for providing me a research internship opportunity at the World Bank to apply this work to study the trade and comparative advantage impacts of the Belt and Road Initiative of China.

${ }^{4}$ I would like to thank Dr. Valerie Cerra (Assistant Director; Western Hemisphere Department, International Monetary Fund) for supervising me on the application of this work to Latin America.

${ }^{5}$ This work is extended to the newly developed firm-heterogeneity CGE model in GTAP (Akgul et al., 2015) to examine the effects of timeliness in trade via transportation infrastructure reform on the export participation and composition. To do this, a two-part econometric model is incorporated to establish the relations in the CGE model between timeliness in trade and technical changes that reduce the fixed cost of entering into the export market and the variable cost of exporting. The paper compares the trade implications across sectors that vary by indirect time sensitivity and across importers using a policy experiment for low income South and East Asia region. This extension is co-authored with Dr. Zeynep Akgul (Visiting Scholar, U.S. International Trade Commission).
}

${ }^{6}$ See Appendix (Figure 9) for shares of primary and processed goods in total commodity exports by region in 2013 for the sample of countries and products used in this paper. 
carried out in Nunn (2007). For each good g, such a measure for indirect time sensitivity is the share weighted average of input specific direct time costs.

Figure 1. Direct and Indirect Measures of Time Sensitivity
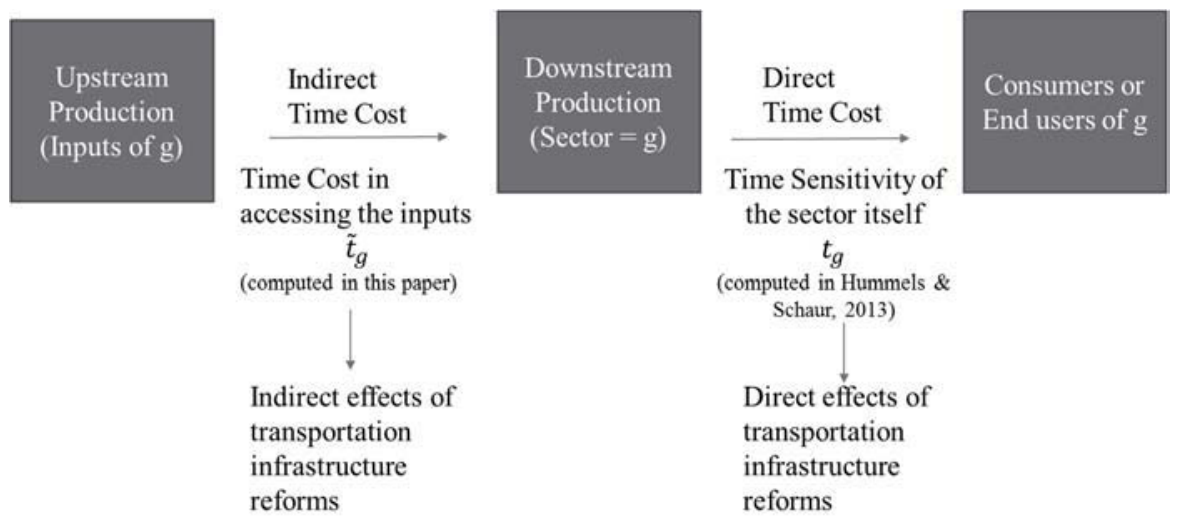

the sector itself

$$
t_{g}
$$

(computed in Hummels \&

Schaur, 2013)

Direct effects of

transportation

infrastructure

reforms

3. Figure 1 provides the summary statistics of direct and indirect measures of time sensitivity by product type. On average, there is an insignificant difference between primary and processed goods in terms of how intensively consumers demand for the timely delivery of products (direct time cost). However, on average, there is a statistically significant difference between primary and processed goods in terms of how intensively producers demand for the timely delivery of their intermediate inputs (indirect time cost). That is, what differentiates the primary goods and processed goods, on average, is not the direct time costs, but the indirect time costs. This is because processed goods compared to primary goods undergo relatively longer production stages (whose length of production chain increases with the degree of processing), and thus, demand for timely delivery of their intermediate inputs for the management of global production networks. In addition, Table 2 shows that goods that use the most time sensitive inputs are processed goods, and these goods mostly use processed inputs, which are again time sensitive. As a result, processed goods face higher indirect time costs than primary goods do, and therefore, transportation infrastructure reform is particularly important for processed goods than for primary goods through the indirect effects of improvement in timeliness in trade.

\section{I examine the effects of time costs of trade on the pattern of trade using the} empirical specification as in Nunn (2007) for a particular period of time. This reduced-form econometric specification, which has been used by many others in the literature (Djankov et al., 2010; Li and Wilson, 2009; Gamberoni et al., 2010; Cosar and Demir, 2014), explains export volumes by the interactions of a product characteristic with a country characteristic. A positive coefficient for the interaction between product specific indirect time sensitivity and country specific quality of transportation infrastructure suggests that countries that can transport goods on time export relatively more in products for which timely delivery of inputs is of a higher concern. Further, I assess if such a comparative advantage pattern is significantly different for primary and processed goods. The main finding of this paper is that any country that can transport goods on time exports relatively more in those products that demand for timely delivery of their inputs, and this comparative advantage pattern is stronger for processed goods than for primary goods. In particular, on average, a 10 percent improvement in the transportation 
infrastructure quality of a country leads to approximately 5.9 percent increment in the export volume of primary goods and 12.8 percent increment in that of processed goods (using IV Results in Table 3 for all products). This paper is then applied to Latin American region to examine if the indirect effects of timeliness in trade is as important for Latin American countries as it is for the rest of the world.

\section{These conclusions have serious developmental policy implications and suggest} important future research directions. First, boosting primary sector-based income (such as agriculture and extraction) is critical for developing countries, where majority of the population participates in the primary activities. For instance, over 70 percent of the population in Nepal is engaged in agriculture and forestry, and about 61 percent of them are women (ILO, 2008). It is important that the developing countries focus their efforts into linking the existing and potential farmers to their consumers and productive inputs through improved transportation. Better access to both upstream and downstream markets via improved transportation (Donaldson and Hornbeck, 2013) help the farmers by increasing their production and sales, and the value of their time sensitive raw agricultural products as the farmers will then be able to reach the market on time and impede the depreciation of quality or freshness of their inputs and final products. This is particularly important for countries like Nepal that is geographically disadvantaged, where it takes about 2 to 5 days for farmers to reach the nearest highway in the remote mountainous region (Nepal Department of Roads Statistics). In fact, this paper shows that each day in time saving while transporting raw vegetables and fruits to consumers and while accessing the intermediate inputs of such agricultural goods are equivalent to a reduction in tariff rate of about 1.024 percent and 1.0028 percent levied on the value of the goods, respectively (See Table 7). Hence, timeliness in trade is imperative in enhancing farm and small agriculture-based business income, particularly for women who represent majority of the agricultural labor force in developing countries.

6. Another policy implication comes from the finding that timeliness in accessing the intermediate inputs is particularly important for processed goods industries due to inputoutput linkages. This indicates that an improvement in transportation infrastructure-hence timeliness and better access to markets (Donaldson and Hornbeck, 2013) — is exceedingly essential to provide an incentive to marginal private firms to enter into processed goods industries that can create higher paying employment opportunities in developing countries (Baniya and Akgul, 2016). Poor countries like Nepal face the challenge of disproportionate distribution of labor force into primary and industrial sectors, which lowers productivity and slows down economic growth. In fact, less than 7 percent of the population in Nepal participates in the industrial sector (ILO, 2008). Therefore, improvement in the ability to access the inputs on time is critical in enhancing private sector investment and innovation in processed agriculture-based industries, to create skilled and higher paying jobs (Michaels, 2008), and to reallocate domestic labor resources into primary and industrial sectors in a productive way. Moreover, increased production in the processing sector drives up the demand for primary goods (intermediate inputs), further increasing the prices of agricultural commodities and overall farm-based income. Furthermore, improved timeliness in trade lowers trade cost, and enhances competitiveness and connectivity, thereby integrating these industries in global value chains (Bekkers, et al., 2015) leading to overall economic growth (Alder, 2012). In addition, developing countries will experience industrialization, urbanization and better access to basic facilities (Baum-Snow, 2007) across regions, including remote and interior parts, thereby 
leading to decentralization of population density across regions (Baum-Snow et al., 2012) and a reduction in inter-regional gaps in prices and wages (Donaldson, 2012) as a result of improved transportation infrastructure.

7. This paper contributes to various strands of literature on the value of time in trade. First, similar to other papers in this literature, this paper incorporates the idea that trade costs include not only tariffs and transport costs, but also time costs. Hummels (2001) is among the first to study time cost distinctly from other trade costs: time cost of one day in transit is equivalent to an ad valorem tariff rate of 0.8 percent, which reduces the probability that a country will export to the U.S. by 1 percent for all goods and 1.5 percent for manufactures. Several studies in this literature (Djankov, Freund and Pham, 2010; Li and Wilson, 2009; Gamberoni, Lanz and Piermartini, 2010) show that time costs have a significant effect on the comparative advantage, particularly in time sensitive industries. In addition, Cosar and Demir (2014) uses geo-referenced data to show how a significant public investment on domestic transportation infrastructure in Turkey leads to its comparative advantage in time sensitive products. For instance, products that are perishable and seasonal in nature face higher time costs, and logistics delays can depreciate the value of perishable and time-sensitive products, which might lead to unwanted costs of holding inventories. Hence, time-sensitive industries in countries that cannot transport goods on time are less likely to produce and export. However, unlike these studies, this paper emphasizes the importance of time costs in influencing producer behavior, and hence the trade pattern, by introducing the idea of indirect time cost arising from input-output linkages that is ignored in the literature in addition to the commonly studied direct time cost. In fact, Villar (2004) shows that the concentration of economic activity is more the consequence of improvements in transportation between upstream and downstream firms than those between firms and consumers - further supporting the importance of indirect time costs on the trade pattern.

\section{Next, this paper adds to the literature on the importance of quality of} transportation infrastructure and timeliness in trade on the international trade and specialization pattern particularly in those industries that have production fragmented into vertical stages and that are highly integrated in global value chains (Hummels, 2001; Nordas, 2007). With increasing product differentiation, vertical specialization and international outsourcing, the importance of non-tariff trade costs in determining trade has increased over time (Miroudot, Lanz and Rigoussis, 2009). Moreover, increasing trade and specialization in intermediate goods have increased the need for timely and effective transport and logistics services (Nordas and Piermartini, 2004). Moreover, timeliness and predictability of delivery times are crucial for intermediate compared to final goods since they are a part of international supply chains (Gamberoni, Lanz and Piermartini, 2010). In fact, industries that follow just-intime business practices and rely on international supply chains face a significant cost, because the entire production process might come to a halt if a single input is missing or if there is a delay in the delivery of the intermediate goods ( $\mathrm{Li}$ and Wilson, 2009). This literature focuses on the costs of holding stocks and inability to respond to consumer orders and defective components. Moreover, the importance of timeliness in delivery and the fulfillment of quality standards, which depend on the availability, cost and quality of transport, communication and other logistics services, in the vertical supply chains has been emphasized by Hummels, Ishii and Yi (2009), Nordas (2003), and Kremer (1993). Following similar idea, this paper is the first 
to examine if timeliness in trade is significantly more important for processed goods than for primary goods through the channels of production networks.

9. A challenge in this empirical study is to find an identification strategy that addresses the potential endogeneity between infrastructure and trade (Martincus and Blyde, 2013; Duranton, Morrow and Turner, 2013). For instance, while road and other logistics improvements might increase export performance of the regions that make a reform, it is also possible that growing trade prospects might lead to transport cost reducing investments in these regions. This paper implements a country's physical geography features (such as the mean elevation and distance to coast) to address the reverse causality between trade and investment in transportation infrastructure quality. Moreover, sectors in which timeliness is important (e.g. chemicals and ferrous metals) trade-off time costs and freight cost, and locate themselves near the source of final demand (Hummels and Schaur, 2013; Evans and Harrigan, 2005). In particular, the time taken to deliver intermediate and final goods causes uncertainty about demand, costs and product characteristics, providing an incentive to upstream and downstream firms to cluster around each other (Harrigan and Venables, 2004). I address this co-location issue (endogeneity between availability of upstream activities in a region and the downstream production and exports) due to the correlation between downstream industrial demand for intermediate inputs and the time cost in accessing the inputs following Hummels and Hillberry (2002). They emphasize both the direct and indirect effects of trade frictions on the trade volume, and suggest controlling for industrial demand for intermediate goods that drives up downstream production and exports, and are correlated with the time costs in accessing the inputs. Omitting this variable from the estimating equation causes the trade barrier variable to pick up both the direct and indirect effects of time costs of trade. Another way to address this issue is to use an extensive set of fixed effects as done in Hummels and Hillberry (2002). In addition, a robust measure of indirect time sensitivity across products is constructed by eliminating the diagonal elements of the input-output matrix to address double counting.

\section{Chapter 1 (Effects of Timeliness on the Trade Pattern between Primary and} Processed Goods) is organized as follows. Section 2 describes the data sources and construction of the measure for indirect factor intensities across products, and Section 3 displays the summary statistics. Section 4 presents and analyzes the empirical framework implemented to examine the effect of improvement in timeliness in trade via transportation infrastructure reform on the trade pattern. Section 5 discusses the reverse causality issue between trade and transportation infrastructure, and Section 6 shows the baseline results with the control for this endogeneity using IV estimations. Section 7 presents several robustness checks, including the magnification effects in the presence of indirect time cost of trade. Section 8 concludes the main findings of this paper, and Section 9 discusses the future work in progress and leads us to Chapter 2 (Effects of Transportation Infrastructure Reform on the Export Participation and Composition using the Firm-Heterogeneity CGE model in GTAP).

\section{Data Sources AND VARIAble Computations}

11. The aggregate export volume by country and by product for the year $2013\left(X_{i g}\right)$ are extracted from the UN Comtrade database. This includes all the available countries and HS-6 digit products. Countries are denoted by $i$ and products are denoted by $g$. The data on countryspecific factor endowments and product-specific (HS-6 classification) factor intensities are from 
UNCTAD Revealed Factor Intensity Indices (RFII) database (2007). The factors included in this database are physical capital $(K)$, human capital $(H)$, land $(M)$ and natural resources $(R)$. We use the logistics performance index of a country as a proxy for the quality of transportation infrastructure $(Q)$ from the World Bank's Logistics Performance Index, 2012 database (See Appendix Figure 12). Direct time sensitivity by 4-digit HS classification are expressed in advalorem terms $\left(t_{g}\right)$, and they are computed in Hummels and Schaur (2013). The UN Broad Economic Categories classification corresponded with 6-digit HS classification can be used to group products into different categories: primary and processed goods. The U.S. input-output table at the IO industry level is obtained from the BEA database (2007), and the country specific input-output tables at the GTAP sectoral level are obtained from GTAP database version 9.

\section{The measure for indirect time sensitivity across products are computed following} the procedure carried out in Nunn (2007) in calculating the measure of contract intensity across industries. First, the U.S. input-output table is used to identify which intermediate goods are used, and in what proportions, in the production of each good g. Next, the input specific direct time sensitivity expressed in ad-valorem terms and computed in Hummels and Schaur (2013) are extracted. The input specific direct time sensitivity or cost is the premium that the demanders of this input, i.e. the firms producing the good $\mathrm{g}$, are willing to pay for one day in time savings in the delivery of the input. Using this information, the measure for indirect time costs across products are computed as follows:

$$
\tilde{t}_{g}=\Sigma_{j}\left[\theta_{j}^{g} * t_{j}\right]
$$

where $\theta_{j}^{g}$ is the share of input $\mathrm{j}$ in the total inputs used in the production of good $\mathrm{g}$, and $t_{j}$ is the input specific direct time cost faced by the firms producing good g. The difference between the measure for time intensity across industries studied in the literature $\left(t_{g}\right)$ and the one studied in this paper $\left(\tilde{t}_{g}\right)$ can be understood in the following way. The direct time cost measure, $t_{g}$, as computed in Hummels and Schaur (2013) and as studied by others, provides a measure for how intensively the good $\mathrm{g}$ is demanded on time, i.e. the premium the consumers or the end-users of good $\mathrm{g}$ are willing to pay for the good $\mathrm{g}$ to arrive one day earlier. However, the indirect time cost measure computed in this paper, $\tilde{t}_{g}$, provides a measure for how time sensitive the bundle of intermediate inputs used in the production of good $g$ is, i.e. how intensively the sector $g$ demands for its inputs on time, or the premium sector $\mathrm{g}$ is willing to pay for its bundle of intermediate inputs $\mathrm{j}$ to arrive one day earlier.

13. Similarly, the Nunn-measure for factor intensities of inputs across products for physical capital, human capital, land and natural resources are computed using the inputoutput information as described above and the data on revealed factor intensity indices obtained from UNCTAD's RFII database (2007). In particular, the measures for physical capital, human capital, land and natural resource intensity of inputs across products are computed as $\tilde{k}_{g}=\Sigma_{j}\left[\theta_{j}^{g} * k_{j}\right] ; \tilde{h}_{g}=\Sigma_{j}\left[\theta_{j}^{g} * h_{j}\right] ; \tilde{m}_{g}=\Sigma_{j}\left[\theta_{j}^{g} * m_{j}\right] ; \tilde{r}_{g}=$ $\Sigma_{j}\left[\theta_{j}^{g} * r_{j}\right]$, respectively. Similar interpretation follows for other factor intensity measures. For instance, $k_{g}$ gives the measure for how physical capital intensive the sector $g$ itself is, whereas, $\tilde{k}_{g}$ gives the measure for how physical capital intensive the bundle of intermediate inputs $\mathrm{j}$ used 
in the sector $\mathrm{g}$ is. The existing literature studies only the direct measures of factor intensities and ignores such indirect measures of factor intensities, and this paper tries fill this gap.

\section{SUMMARY STATISTICS}

\section{Table 1. Measure for Time Sensitivity Across Products}

Direct Time Intensity: $t_{g}$ (in ad-valorem terms)

$\begin{array}{cccccc}\text { Goods } & \text { \# of HS6 } & \text { Mean } & \text { Std. Dev. } & \text { Min } & \text { Max } \\ \text { Total } & 3,516 & 0.0132 & 0.0182 & 3.40 \mathrm{E}-06 & 0.6066 \\ \text { Primary } & 169 & 0.0179 & 0.0409 & 1.16 \mathrm{E}-04 & 0.4821 \\ \text { Processed } & 1,747 & 0.0157 & 0.0204 & 3.40 \mathrm{E}-06 & 0.6066\end{array}$

Indirect Time Intensity: $t^{g}$ (in ad-valorem terms)

$\begin{array}{cccccc}\text { Goods } & \text { \# of HS6 } & \text { Mean } & \text { Std. Dev. } & \text { Min } & \text { Max } \\ \text { Total } & 2,391 & 0.0077 & 0.0120 & 3.03 \mathrm{E}-07 & 0.0524 \\ \text { Primary } & 122 & 0.0038 & 0.0033 & 1.89 \mathrm{E}-05 & 0.0194 \\ \text { Processed } & 1,162 & 0.0136 & 0.0148 & 3.03 \mathrm{E}-07 & 0.0524\end{array}$

Note: The direct time sensitivity measure, $t \_g$, as computed in Hummels and Schaur (2013), provides a measure for how intensively the good $\mathrm{g}$ is demanded by consumers on time, i.e. the premium the consumers or the end-users of good $\mathrm{g}$ are willing to pay for the good $g$ to arrive one day earlier. However, the indirect time sensitivity measure computed in this paper, $\tilde{t} \_g$, provides a measure for how time sensitive the bundle of intermediate inputs used in the production of good $g$ is, i.e. how intensively the sector $g$ or the producer demands for its inputs on time, or the premium sector $g$ is willing to pay for its bundle of intermediate inputs $j$ to arrive one day earlier.

14. Table 1 provides the average time sensitivity of products and that of their bundle of intermediate inputs for different product groups: processed goods and primary goods. ${ }^{7} \mathrm{We}$ find that the difference in the direct time costs $t_{g}$ between primary and processed goods, on average, is not significant; however, on average, there is a significant difference in the measure for time intensity of the inputs (indirect time costs: $\tilde{t}_{g}$ ) between primary and processed goods. This implies that, on average, primary and processed goods do not differ significantly based on the intensity with which consumers demand for the timely delivery of goods. However, on average, primary and processed goods differ significantly based on the intensity with which the producers demand for the timely delivery of their inputs. This further supports the hypothesis that processed goods producers, on average, face higher indirect time costs arising through input-output linkages than primary goods producers do.

15. Table 2 below presents the six most time sensitive inputs, in order, i.e. the products that have the highest measure for time sensitivity $\boldsymbol{t}_{\boldsymbol{g}}$ as computed in Hummels and Schaur (2013). We see that all of these most time sensitive inputs are processed goods according to BEA classification. In addition, along with these inputs, a list of products that use these inputs in high proportion compared to other products are also provided. We see that the products that use

\footnotetext{
${ }^{7}$ The summary statistics includes only those countries and products that are in the sample used in this paper. The sample contains all the available countries in UN Comtrade database (2013) and all the available products in Hummels and Schaur's time sensitivity computation.
} 
the most time sensitive inputs are processed goods, and these processed goods mostly use processed inputs compared to primary inputs.

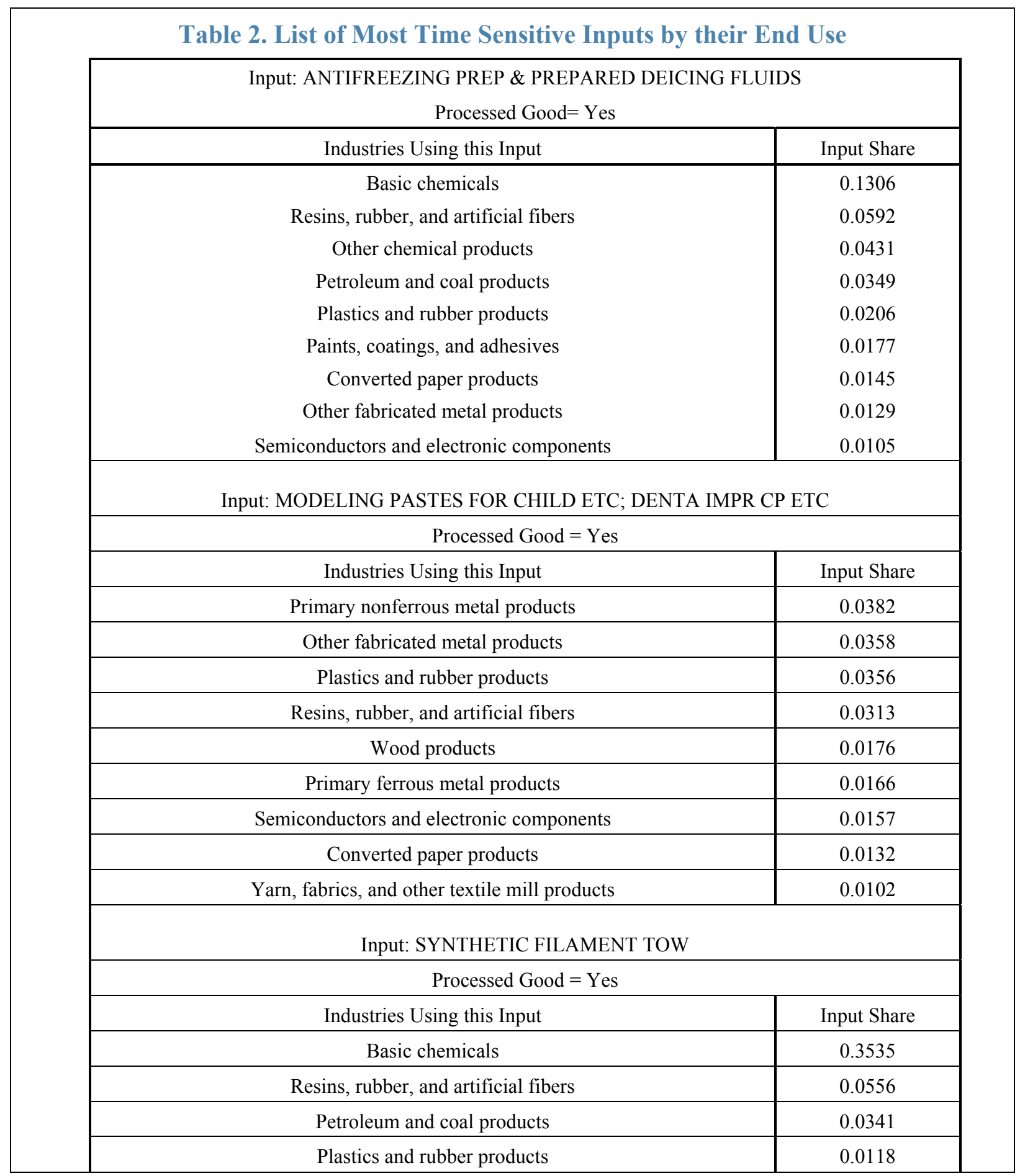




\begin{tabular}{|c|c|}
\hline \multicolumn{2}{|c|}{$\begin{array}{l}\text { Input: OPTICAL ELEMENTS, MOUNTED; PARTS \& ACCESSORIES } \\
\text { Processed Good = Yes }\end{array}$} \\
\hline Industries Using this Input & Input Share \\
\hline Other fabricated metal products & 0.0577 \\
\hline Semiconductors and electronic components & 0.0433 \\
\hline Plastics and rubber products & 0.0266 \\
\hline Other electrical equipment and components & 0.0257 \\
\hline Primary ferrous metal products & 0.0206 \\
\hline Electrical equipment & 0.0179 \\
\hline Architectural and structural metal products & 0.0171 \\
\hline
\end{tabular}

\section{The summary statistics includes only those countries and products that are} included in the sample used in this paper. Figure 2 provides a box plot of regional logistics performance index (LPI) in order. Sub-Saharan Africa and South Asia have the lowest levels of LPI, whereas, East Asia and Pacific, Europe and Central Asia, and North America have the highest levels of LPI. This paper provides an application to Latin American region, which has the level of LPI around the world average. Figures 3 and 4, respectively, plot the countryspecific shares of primary and processed goods in 2013 total commodity exports by LPI (2012). Figure 3 shows that countries with higher level of LPI tend to export relatively less primary goods. Next, Figure 4 shows that the share of processed commodities in total exports rises as the LPI increases until the LPI level of slightly over 3. After that level of LPI, the share of processed commodities in total exports falls as well, implying that the share of commodities other than primary or processed goods (e.g. higher value added goods) in total exports increases as the LPI increases. Figures 3 and 4 highlight the Latin American (LA) countries to show where LA countries stand against the rest of the world in terms of LPI and export shares of primary and processed goods for the application to Latin American region later in the paper. 

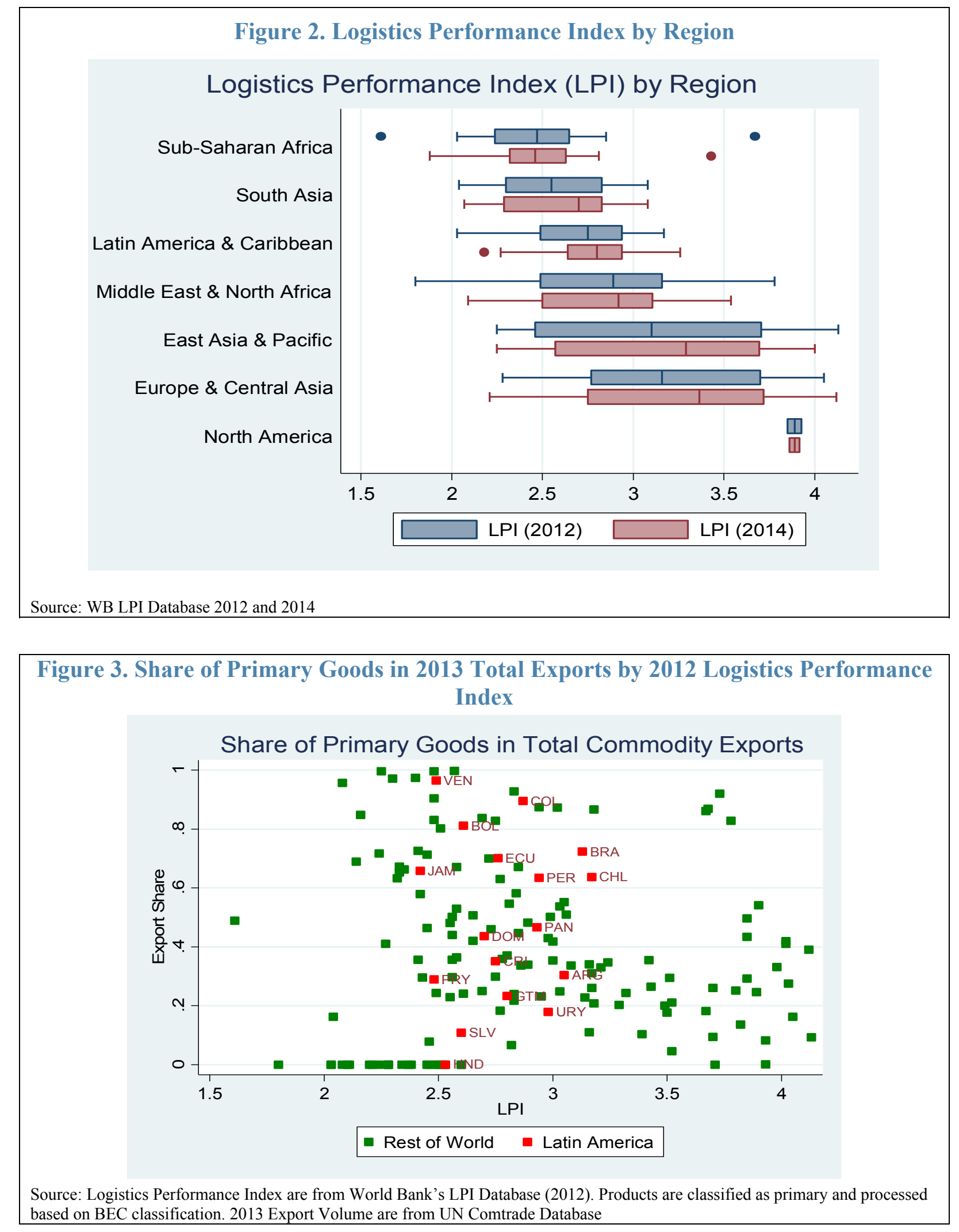

CInternational Monetary Fund. Not for Redistribution 

Figure 4. Share of Processed Goods in 2013 Total Exports by 2012 Logistics
Performance Index

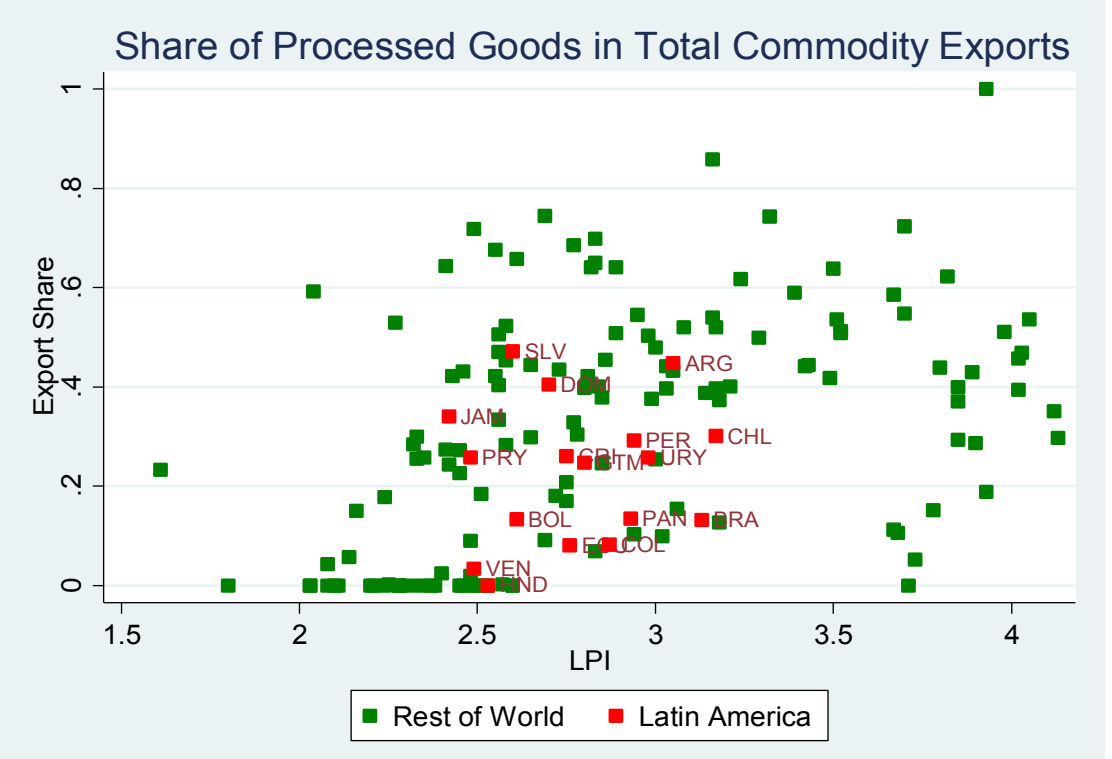

Source: Logistics Performance Index are from World Bank's LPI Database (2012). Products are classified as primary and processed based on BEC classification. 2013 Export Volume are from UN Comtrade Database. The summary statistics includes only those countries and products that are included in the sample used in this paper.

\section{Figure 5. Country-Specific Weighted Average Upstreamness of Products by LPI}

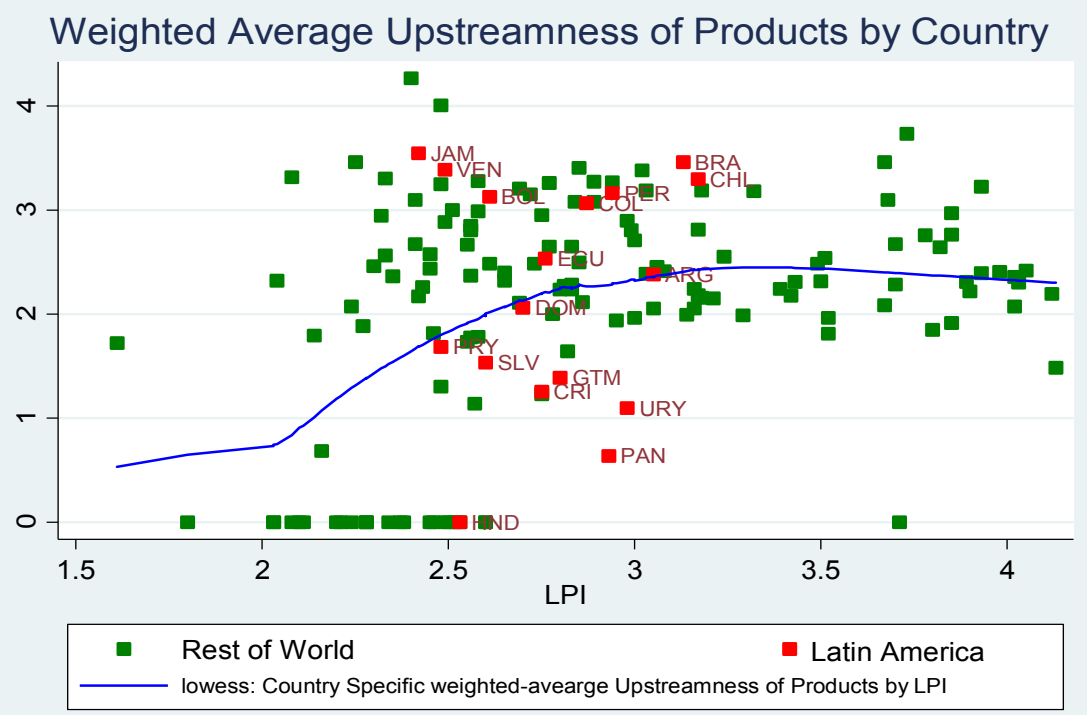

Source: Measure of upstreamness of products are extracted from computations in Fally (2012). This index provides a measure for how far a product is from its final use. Weights are export shares of products.. 


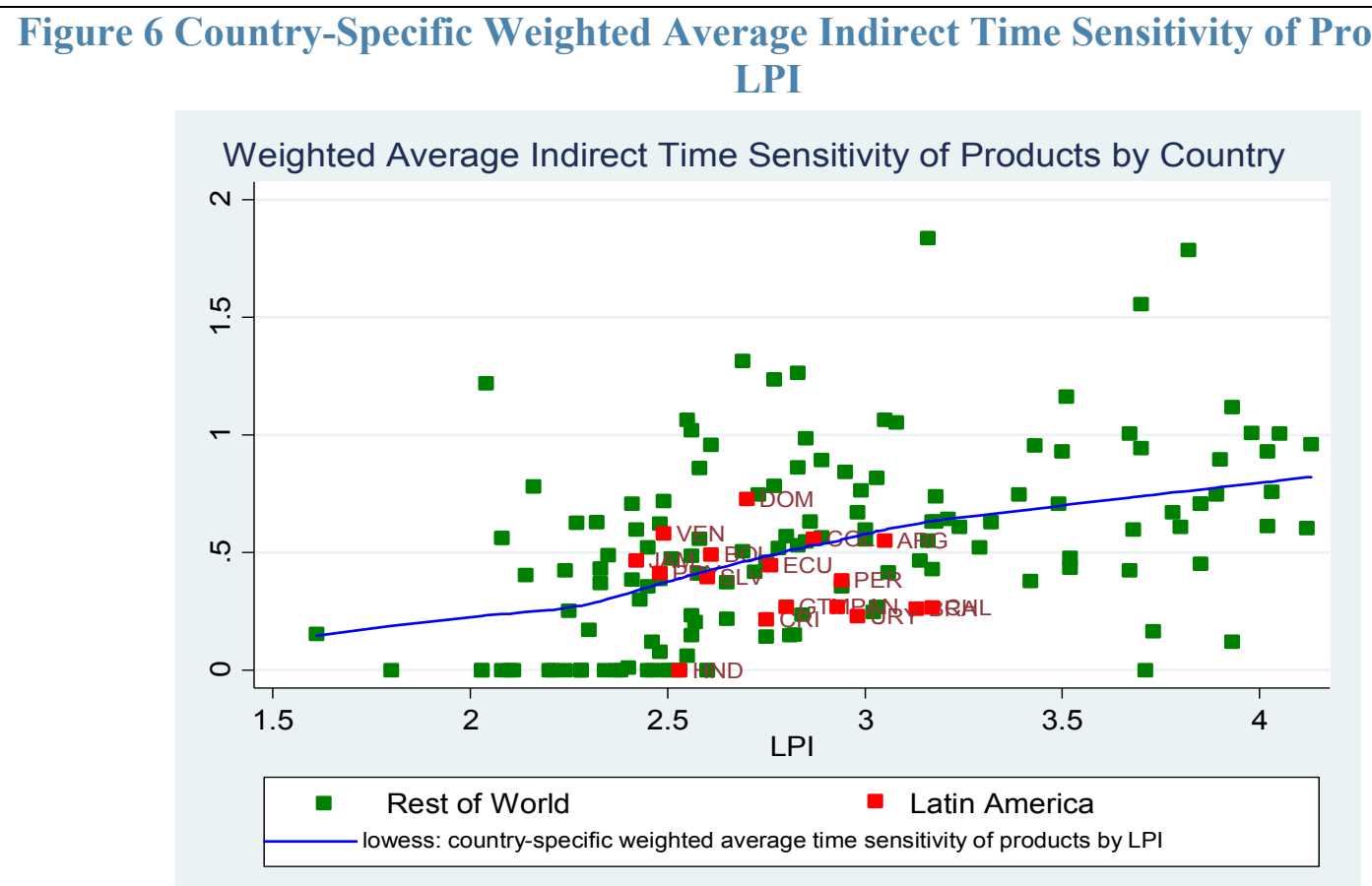

\section{EMPIRICAL FrAMEWORK}

17. Following the empirical specification as in Nunn (2007), I examine how a country's ability to transport goods on time determines its comparative advantage in products that value timely delivery of their inputs, and therefore, the trade pattern between primary and processed goods. Similar specification has been used in other papers that carry out a similar analysis focusing on direct time costs (e.g. Djankov, Freund \& Pham, 2010; Li \& Wilson, 2009; Gamberoni, Lanz \& Piermartini, 2010). I adopt this empirical specification that explains export volumes by the interactions of a country specific factor endowment with a product specific factor intensity.

\section{Baseline Framework:}

$$
\begin{gathered}
\ln X_{i g}=\mu_{i}+\eta_{g}+\lambda \boldsymbol{\Omega}_{\boldsymbol{i}} \boldsymbol{V}_{\boldsymbol{g}}+\boldsymbol{\gamma} \boldsymbol{\Omega}_{\boldsymbol{i}} \widetilde{\boldsymbol{V}}_{\boldsymbol{g}}+\lambda_{4} Q_{i} * t_{g}+\gamma_{4} Q_{i} * \tilde{t}_{g}+\varepsilon_{i g}, \text { where } \\
\boldsymbol{\lambda} \boldsymbol{\Omega}_{\boldsymbol{i}} \boldsymbol{V}_{\boldsymbol{g}}=\lambda_{0}+\lambda_{1} \ln K_{i} * \ln k_{g}+\lambda_{2} \ln H_{i} * \ln h_{g}+\lambda_{3} \ln R_{i} * \ln r_{g} \\
\boldsymbol{\gamma} \boldsymbol{\Omega}_{\boldsymbol{i}} \widetilde{\boldsymbol{V}}_{\boldsymbol{g}}=\gamma_{0}+\gamma_{1} \ln K_{i} * \ln \tilde{k}_{g}+\gamma_{2} \ln H_{i} * \ln \tilde{h}_{g}+\gamma_{3} \ln R_{i} * \ln \tilde{r}_{g}
\end{gathered}
$$

$X_{i g}$ is the 2013 export volume of commodity $g$ from country $i$ to the world, and $\mu_{i}$ and $\lambda_{g}$ are country specific fixed effects and product specific fixed effects, respectively. The control variables on the right hand side of this equation are defined in Section 2 (data and variable computation), where $K, H$ and $R$ represent physical capital, human capital and natural resource endowment across countries, and the small letters $k, h$ and $r$ represent corresponding factor intensities across products. The variables of interest here are as follows. 
$Q_{i}$ represents the infrastructure component of the logistics performance index obtained from the World Bank's LPI database (2012). Next, $t_{g}$ represents the direct time costs of trade obtained from the calculations in Hummels and Schaur (2013); whereas, $\tilde{t}_{g}$ represents the indirect time costs of trade computed in this paper using input-output information and input specific direct time costs.

The first value addition of this paper is the inclusion of the terms $\boldsymbol{\gamma} \boldsymbol{\Omega}_{\boldsymbol{i}} \widetilde{\boldsymbol{V}}_{\boldsymbol{g}}$ and $\gamma_{4} Q_{i} * \tilde{t}_{\boldsymbol{g}}$ (ignored in the literature) in this empirical model to assess the effect of improvement in timeliness in accessing the intermediate inputs on the trade pattern. Here, the total effect of improvement in timeliness in trade (through the transportation infrastructure reforms) on the export volume is the sum of the two terms:

$$
\lambda_{4} * t_{g}+\gamma_{4} * \tilde{t}_{g}, \text { where }
$$

$\lambda_{4} * t_{g}$ represents the direct effect of transportation infrastructure reforms, while $\gamma_{4} * \tilde{t}_{g}$ represents the indirect effect of transportation infrastructure reforms arising through the input-output linkages. The direct effect of reforms for a sector $g$ comes from the improvement in the ability to transport its final product $g$ to its consumers on time, whereas, the indirect effect of such reforms for the sector $g$ comes from the improvement in the ability to access the intermediate inputs $j$ used in the production of the sector's final product $g$ from the upstream industries on time. This indirect effect has not been studied in the literature, and therefore, I try to fill this gap through this paper.

The positive coefficient of each interaction term indicates that a country exports relatively more in those industries that intensively use the factor, which the country is abundantly endowed with. For instance, if the coefficient of interest $\left(\gamma_{4}\right)$ is positive, it indicates that countries that can transport goods on time export relatively more in industries for which timely delivery of their inputs is of a higher concern. Similarly, if the coefficient $\left(\lambda_{4}\right)$ is positive, it indicates that countries that can transport goods on time export relatively more in industries that face higher direct time costs. Hence, in this paper, I am assessing two different comparative advantage patterns. The former comparative advantage arises due to the indirect effect of timeliness in trade, while the latter arises due to the direct effect of timeliness in trade. I estimate both the coefficients $\lambda_{4}$ and $\gamma_{4}$ (as opposed to other papers in the literature) to estimate both the direct effect $\left(\lambda_{4} * t_{g}\right)$ and the indirect effect $\left(\gamma_{4} * \tilde{t}_{g}\right)$ of transportation infrastructure reforms on the export pattern, respectively. This also enables us to compare the size of the direct and indirect effects of transportation infrastructure reforms on the trade pattern. The coefficients of these interaction terms capture only the effect of country's characteristic on the trade pattern and not on the export volume. The latter effect is captured completely once we incorporate the country and product specific fixed effects $\left(\mu_{i}\right.$ and $\left.\lambda_{g}\right)$ in addition.

Next, I wish to examine if timeliness in trade is an important source of comparative advantage for processed goods than for primary goods. Furthermore, I wish to examine which of the two channels discussed above is relatively more important in determining the comparative advantage in processed goods. We saw earlier that, on average, primary goods and processed goods are significantly different in terms of indirect time costs, $\tilde{t}_{g}$, but not in 
terms of direct time costs, $t_{g}$. Hence, I suspect that the comparative advantage pattern between processed goods and primary goods arises from the indirect effects, more than from the direct effects, of the improvement in timeliness in trade through transportation infrastructure reforms. To test this, I run the baseline regression separately for the primary goods and processed goods, and compare the direct and indirect effects of transportation infrastructure reforms between the two types of goods. The results for these baseline equations are reported in Table 3 under Section 6 . Note that this can also be achieved by including the terms $\lambda_{5}\left(Q_{i} * t_{g} * I\right)$ and $\gamma_{5}\left(Q_{i} * \tilde{t}_{g} * I\right)$ in the above regression, where $I$ is a dummy that equals 1 if a good is a processed good and 0 if it is a primary good. This also tests whether the comparative advantage pattern arising through direct and indirect effects of transportation infrastructure reforms are significantly different for processed goods compared to primary goods. In particular, a positive estimate of $\gamma_{5}$ indicates that timeliness in transporting intermediate inputs is an important source of comparative advantage for processed goods than for primary goods. Finally, to control for the endogeneity between trade and transportation infrastructure, I use the instrumental variable approach, which I will discuss in the next section.

\section{ENDOGENEITY}

\section{A. Control for Reverse Causality between Trade and Infrastructure}

\section{A fundamental problem that arises when carrying out such an analysis is the reverse causality between trade and transportation infrastructure. In particular, a country that has a better trade prospect or that plans to improve its current trade flows also invests more on transportation infrastructure. Hence, although transportation infrastructure reforms might increase trade flows, it is also possible that conditions of trade flows in a country can provide an incentive to invest in transportation infrastructure.}

\section{To address this problem, I extract the data on physical geography features} across countries obtained from the country geography database provided by Portland State University. A country's physical geography features are then used as instruments for its quality of transport infrastructure. This database provides information on mean elevation $\left(E_{i}\right)$, mean distance to the nearest coastline or sea navigable river $\left(D_{i}\right)$, percentage of land area within $100 \mathrm{~km}$ of ice free coast or sea navigable river, percentage of population within $100 \mathrm{~km}$ of ice free coast or sea navigable river, distance from a country's centroid to the nearest coast or sea navigable river, and percentage of land area in the geographical tropics. Among these variables, I extract the first two for the IV estimation. These variables are valid instruments, because, first, these geographical features are clearly exogenous to trade. Next, these geographical features will affect the ability of a country to transport goods on time, because countries with higher $E_{i}$ (perhaps due to the presence of a large quantity of mountains) and higher $D_{i}$ mostly have poor road networks and sea networks, respectively. Further, the geographical features of a country have no direct effect on the exports of the country; hence they are excludable. The results for the second stage of the 2SLS estimation for different product groups using these instruments are reported in Table 3 in Section 6. I carry out similar IV estimations across different product groups to examine if timeliness in trade is an important source of comparative advantage for processed goods. 


\section{Instrumental Variable Approach}

- First Stage:

$$
\begin{aligned}
& Q_{i} * t_{g}=\alpha_{0}+\mu_{i}+\eta_{g}+\boldsymbol{\iota} \boldsymbol{\Omega}_{\boldsymbol{i}} \boldsymbol{V}_{\boldsymbol{g}}+\boldsymbol{\alpha} \boldsymbol{\Omega}_{\boldsymbol{i}} \widetilde{\boldsymbol{V}}_{\boldsymbol{g}}+\iota_{4} T_{i} * t_{g}+\alpha_{4} T_{i} * \tilde{t}_{g}+v_{i g} \\
& Q_{i} * \tilde{t}_{g}=\beta_{0}+\mu_{i}+\eta_{\boldsymbol{g}}+\boldsymbol{\kappa} \boldsymbol{\Omega}_{\boldsymbol{i}} \boldsymbol{V}_{\boldsymbol{g}}+\boldsymbol{\beta} \boldsymbol{\Omega}_{\boldsymbol{i}} \widetilde{\boldsymbol{V}}_{\boldsymbol{g}}+\kappa_{4} T_{i} * t_{g}+\beta_{4} T_{i} * \tilde{t}_{g}+\delta_{i g}
\end{aligned}
$$

- Second Stage:

$$
\ln X_{i g}=\gamma_{0}+\mu_{i}+\eta_{g}+\boldsymbol{\lambda} \boldsymbol{\Omega}_{\boldsymbol{i}} \boldsymbol{V}_{\boldsymbol{g}}+\boldsymbol{\gamma} \boldsymbol{\Omega}_{\boldsymbol{i}} \widetilde{\boldsymbol{V}}_{\boldsymbol{g}}+\lambda_{4} \widehat{Q_{\imath} * t_{g}}+\gamma_{4} \widehat{Q_{l} * \tilde{t}_{g}}+\varepsilon_{i g}
$$

\begin{tabular}{|c|c|c|c|c|c|c|c|}
\hline & LPI & Mean Elevation & $\begin{array}{c}\text { Mean } \\
\text { Distance to } \\
\text { Coast }\end{array}$ & $\begin{array}{l}\text { Land Area } \\
\text { Closer to } \\
\text { Coast }\end{array}$ & $\begin{array}{l}\text { Population } \\
\text { Closer to } \\
\text { Coast }\end{array}$ & $\begin{array}{c}\text { Distance to } \\
\text { Coast from } \\
\text { Centroid }\end{array}$ & $\begin{array}{l}\text { Land Area in } \\
\text { Geographical } \\
\text { Tropics }\end{array}$ \\
\hline LPI & 1 & & & & & & \\
\hline Mean Elevation & -0.2421 & 1 & & & & & \\
\hline $\begin{array}{l}\text { Mean Distance } \\
\text { to Coast }\end{array}$ & -0.3192 & 0.3656 & 1 & & & & \\
\hline $\begin{array}{l}\text { Land Area Closer } \\
\text { to Coast }\end{array}$ & 0.4028 & -0.455 & -0.6611 & 1 & & & \\
\hline $\begin{array}{l}\text { Population Closer } \\
\text { to Coast }\end{array}$ & 0.4897 & -0.521 & -0.6586 & 0.917 & 1 & & \\
\hline $\begin{array}{l}\text { Distance to Coast } \\
\text { from Centroid } \\
\text { Land Area in } \\
\text { Geographical }\end{array}$ & -0.1776 & 0.2832 & 0.9148 & -0.5837 & -0.542 & 1 & \\
\hline Tropics & -0.489 & -0.1163 & -0.0147 & -0.1641 & -0.1685 & -0.1092 & 1 \\
\hline
\end{tabular}

\section{Correlation Between Transportation Infrastructure and Physical Geography}

I extract the data on physical geography features across countries from the country geography database provided by Portland State University. This database provides information on mean elevation $\left(E_{i}\right)$, mean distance to the nearest coastline or sea navigable river $\left(D_{i}\right)$, percentage of land area within $100 \mathrm{~km}$ of ice free coast or sea navigable river, percentage of population within $100 \mathrm{~km}$ of ice free coast or sea navigable river, distance from a country's centroid to the nearest coast or sea navigable river, and percentage of land area in geographical tropics. Among these variables, I extract the first two for the IV estimation. LPI stands for the logistics performance index extracted from the World Bank's LPI database (2012). 


\section{Results}

\begin{tabular}{|c|c|c|c|c|c|c|c|c|}
\hline \multicolumn{9}{|c|}{ All Countries } \\
\hline & \multicolumn{2}{|c|}{ All Products } & \multicolumn{2}{|c|}{ Primary \& Processed } & \multicolumn{2}{|c|}{ Processed Goods } & \multicolumn{2}{|c|}{ Primary Goods } \\
\hline \multirow[t]{2}{*}{ VARIABLES } & \multicolumn{2}{|c|}{ Export Volume } & \multicolumn{2}{|c|}{ Export Volume } & \multicolumn{2}{|c|}{ Export Volume } & \multicolumn{2}{|c|}{ Export Volume } \\
\hline & OLS & IV & OLS & IV & OLS & IV & OLS & IV \\
\hline$Q_{i} * t_{g}$ & $0.111^{* * *}$ & $0.172 * * *$ & $0.151 * * *$ & $0.200 * * *$ & $0.165 * * *$ & $0.185^{* * *}$ & $-0.318^{* *}$ & -0.398 \\
\hline (Direct Effect) & $(0.0241)$ & $(0.0594)$ & $(0.0268)$ & $(0.0660)$ & $(0.0278)$ & $(0.0667)$ & $(0.126)$ & $(0.307)$ \\
\hline$Q_{i} * \tilde{t}_{g}$ & $0.318^{* * *}$ & $0.742 * * *$ & $0.477 * * *$ & $1.140 * * *$ & $0.384 * * *$ & $0.921 * * *$ & 0.0538 & -1.699 \\
\hline (Indirect Effect) & $(0.0549)$ & $(0.127)$ & $(0.0614)$ & $(0.143)$ & $(0.0627)$ & $(0.146)$ & $(0.568)$ & $(1.732)$ \\
\hline $1^{\text {st }}$ Stg F-stat & & $154.16^{* * *}$ & & $143.38^{* * *}$ & & $74.51 * * *$ & & $94.20 * * *$ \\
\hline $1^{\text {st }}$ Stg F-stat & & $2623.79 * * *$ & & $2539.37 * * *$ & & $2498.93 * * *$ & & $65.40 * * *$ \\
\hline Observations & 130,265 & 53,068 & 80,484 & 32,676 & 67,810 & 27,482 & 12,674 & 5,194 \\
\hline R-squared & 0.661 & 0.650 & 0.546 & 0.535 & 0.569 & 0.561 & 0.464 & 0.437 \\
\hline \multicolumn{9}{|c|}{ Latin America } \\
\hline & \multicolumn{2}{|c|}{ All Products } & \multicolumn{2}{|c|}{ Primary \& Processed } & \multicolumn{2}{|c|}{ Processed Goods } & \multicolumn{2}{|c|}{ Primary Goods } \\
\hline \multirow[t]{2}{*}{ VARIABLES } & \multicolumn{2}{|c|}{ Export Volume } & \multicolumn{2}{|c|}{ Export Volume } & \multicolumn{2}{|c|}{ Export Volume } & \multicolumn{2}{|c|}{ Export Volume } \\
\hline & OLS & IV & OLS & IV & OLS & IV & OLS & IV \\
\hline$Q_{i} * t_{g}$ & $0.585^{* * *}$ & $0.367 * *$ & $0.402 * * *$ & 0.236 & $0.436 * * *$ & $0.271^{*}$ & -1.250 & -1.278 \\
\hline (Direct Effect) & $(0.151)$ & $(0.150)$ & $(0.151)$ & $(0.158)$ & $(0.149)$ & $(0.153)$ & $(0.851)$ & $(0.993)$ \\
\hline$Q_{i} * \tilde{t}_{g}$ & -0.190 & 0.115 & 0.312 & 0.555 & -0.0316 & 0.251 & 3.215 & 6.320 \\
\hline (Indirect Effect) & $(0.336)$ & $(0.365)$ & $(0.378)$ & $(0.413)$ & $(0.382)$ & $(0.417)$ & (3.988) & $(4.639)$ \\
\hline $1^{\text {st }}$ Stg F-stat & & $108.52 * * *$ & & $106.46^{* * *}$ & & $50.56 * * *$ & & $97.87 * * *$ \\
\hline $1^{\text {st }}$ Stg F-stat & & $2990.18^{* * *}$ & & $3102.72 * * *$ & & $3104.81 * * *$ & & $41.36 * * *$ \\
\hline Observations & 19,789 & 18,705 & 11,797 & 11,241 & 10,010 & 9,551 & 1,787 & 1,690 \\
\hline R-squared & 0.639 & 0.642 & 0.503 & 0.509 & 0.520 & 0.527 & 0.430 & 0.432 \\
\hline \multicolumn{9}{|c|}{$\begin{array}{l}\text { Dependent variable is } 2013 \text { aggregate export volume. All the regressions control for other factor interactions, and include country and product fixed } \\
\text { effects. Physical geography features are used as instruments for infrastructure. The direct effect of reforms for a sector g comes from the improvement } \\
\text { in country i's ability to transport its final product } \mathrm{g} \text { on time, whereas, the indirect effect of reforms for the sector } \mathrm{g} \text { comes from the improvement in } \\
\text { its ability to access the intermediate inputs } \mathrm{j} \text { used in the production of good } \mathrm{g} \text { on time. A positive coefficient of the variable } Q_{i} * t_{g} \text { implies a } \\
\text { comparative advantage in products that are time sensitive; whereas, a positive coefficient of } Q_{i} * \tilde{t}_{g} \text { implies a comparative advantage in products } \\
\text { that use time sensitive inputs. Robust standard errors in parentheses. }{ }^{* * *} \mathrm{p}<0.01,{ }^{* *} \mathrm{p}<0.05,{ }^{*} \mathrm{p}<0.1 \text {. }\end{array}$} \\
\hline
\end{tabular}


20. Table 3 presents the regression results for the baseline equation for different product groups. It reports the coefficients for only those comparative advantage sources that are of interest to this paper: $Q_{i} * t_{g}$ and $Q_{i} * \tilde{t}_{g}$. We can see that the coefficient estimate for the variable of interest, $Q_{i} * t_{g}$ and $Q_{i} * \tilde{t}_{g}$, are positive and statistically significant when I run the regression for the sample that includes all products, both primary and processed goods, and processed goods only. In addition to the conclusions of the literature (usual sources of comparative advantage), I find that countries that can transport goods on time export relatively more in industries for which timely delivery of inputs is of a higher concern. Secondly, both the direct and indirect effects of transportation infrastructure reforms are positive and significant for the first three product groups, however, the indirect effects arising through input-output linkages are larger than the direct effects of reforms.

21. Next, I run this regression separately for processed and primary goods to test if this comparative advantage pattern is stronger for processed goods. Both the direct and indirect effects are significant for processed goods; in particular, I find that the indirect effects of transportation infrastructure reforms for processed goods are larger than the direct effects. However, the effect of timeliness in trade seems negative (contraction) or insignificant for primary goods. Hence, countries with better quality of transport infrastructure specialize in industries that have a higher value for timely delivery of their inputs, and this comparative advantage pattern is stronger for processed goods than for primary goods, because processed goods face higher time costs in accessing their inputs than primary goods do. Further, I find that timeliness in trade is particularly important for processed goods than for primary goods.

22. This result is further confirmed after controlling for reverse causality using IV estimation approach: physical geography features of a country as instruments for its quality of transportation infrastructure in Table 3. In particular, the coefficients of interest are all positive and significant except for the sample containing primary goods only. Hence, from these exercises, I conclude that countries with higher quality of transportation infrastructure specialize relatively more in products that value timely delivery of their inputs. Moreover, timeliness is particularly an important source of comparative advantage for processed goods compared to primary goods as processed goods undergo larger production stages. However, one might suspect that the coefficients are slightly magnified in the IV estimation results. So, I try to address the co-location between upstream and downstream industries in the presence of indirect time costs that is possibly leading to this magnification effect following Hummels and Hillberry (2002) in the next section. Before we address this issue, I present below the analysis of results for Latin America.

23. Table 3 shows that only the direct effects of transportation infrastructure reforms seem to be positive and significant for Latin American countries, when I run the regression for the sample containing all products, primary and processed goods, and processed goods only. Improvement in timeliness in trade do not seem to have significant indirect effects, arising through input-output linkages, on the trade pattern in Latin America. However, Figure 2 shows that the 2012 LPI level of Latin America ranges from slightly over 2 to 3.17 , which indicates that the average level of upstreamness, and the 
average direct and indirect time sensitivity of products of Latin America are rising with LPI . Hence, I now examine how the share of different types of commodities (e.g. primary, processed and higher value-added goods) in Latin America changes with the level of LPI to investigate if the existing production structure in Latin America is giving rise to such a different trade impact compared to the rest of the world. Figure 6 shows that within Latin American countries with low levels of LPI (less than 2.5) we see a sharp fall in the share of processed goods (which face larger indirect time costs) with a rise in LPI. This is a very different pattern in Latin America compared to the rest of the world with a similar level of LPI. Hence, it is possible that such contrasting results in Table 3 for Latin America was identified off of this group of Latin American countries. Therefore, I next examine if the indirect effects of transportation infrastructure reforms are significantly positive for the sample of Latin American countries with higher levels of income or higher levels of LPI. Table 4 reports the results with such restricted samples for Latin America.

Figure 7. 2013 Composition of Exports by 2012 Logistics Performance Index (World vs Latin America)

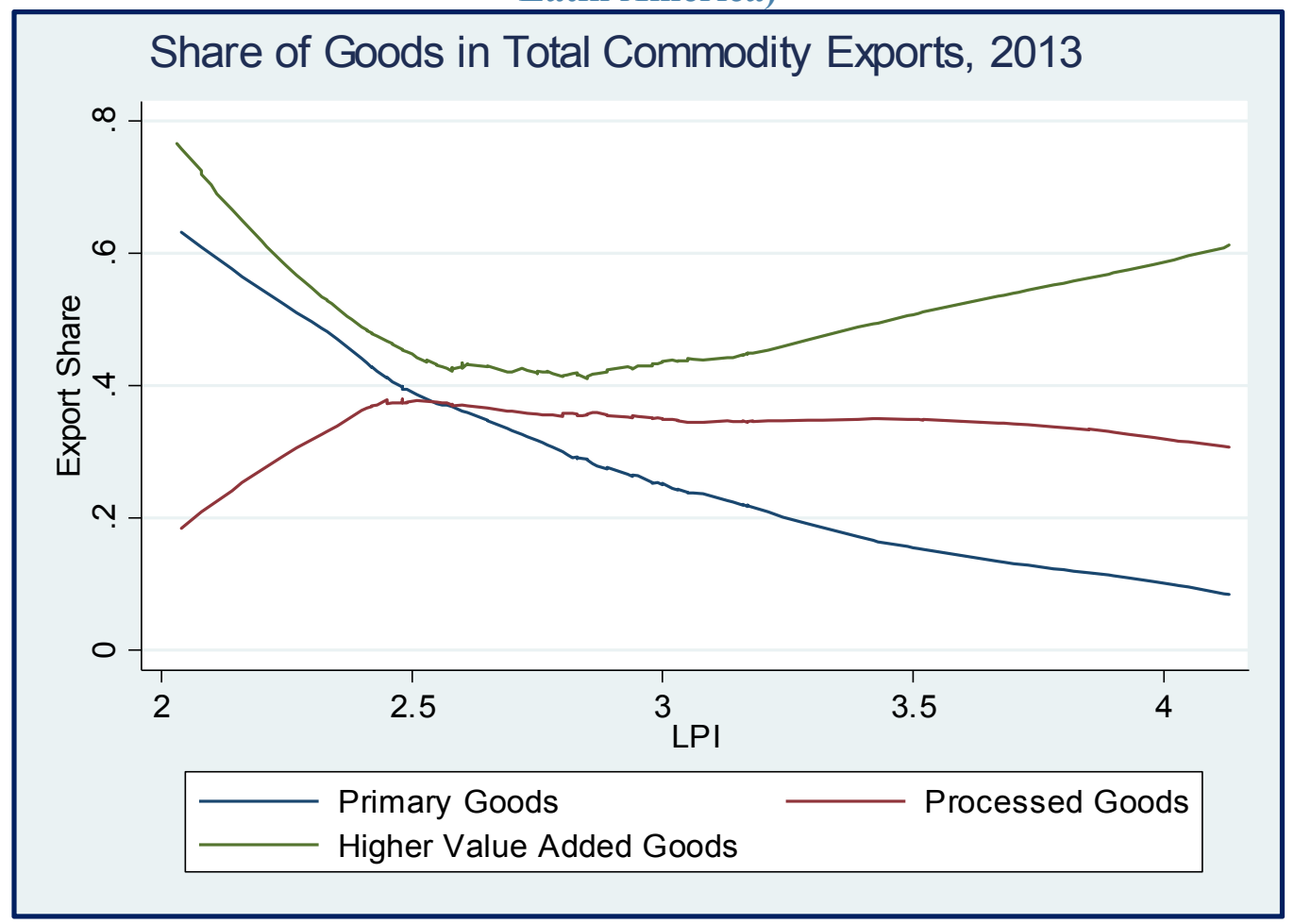

\footnotetext{
${ }^{8}$ See Figure 5, 6 and 10.
} 


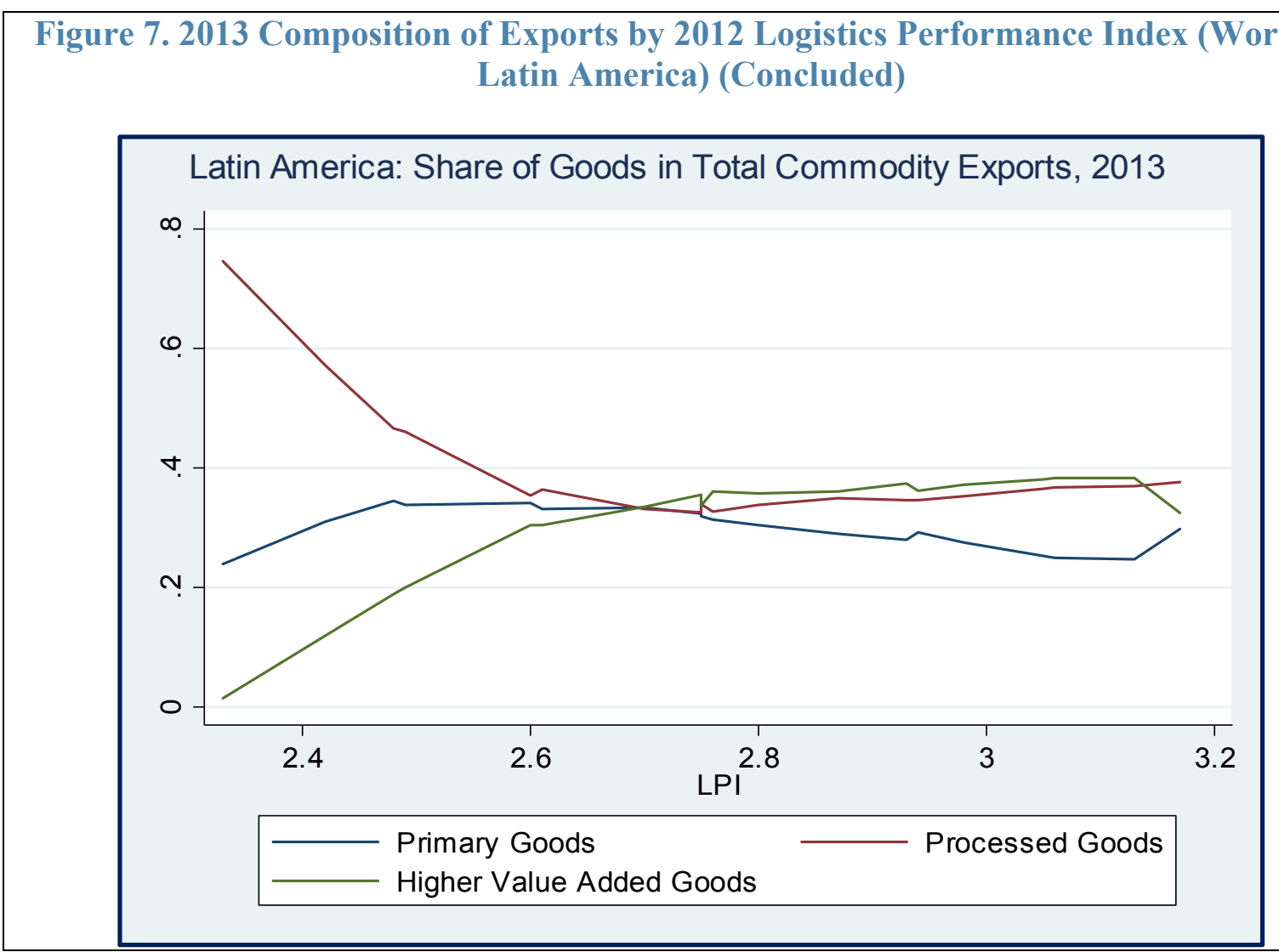




\begin{tabular}{|c|c|c|c|c|c|c|c|c|}
\hline \multicolumn{9}{|c|}{ LAC Countries with LPI Level > 2.5} \\
\hline & \multicolumn{2}{|c|}{ All Products } & \multicolumn{2}{|c|}{ Primary \& Processed } & \multicolumn{2}{|c|}{ Processed Goods } & \multicolumn{2}{|c|}{ Primary Goods } \\
\hline VARIABLES & \multicolumn{2}{|c|}{ Export Volume } & \multicolumn{2}{|c|}{ Export Volume } & \multicolumn{2}{|c|}{ Export Volume } & \multicolumn{2}{|c|}{ Export Volume } \\
\hline & OLS & IV & OLS & IV & OLS & IV & OLS & IV \\
\hline $\begin{array}{c}Q_{i} * t_{g} \\
\text { (Direct Effect) }\end{array}$ & $\begin{array}{c}0.475^{* * *} \\
(0.147)\end{array}$ & $\begin{array}{c}0.444 * * * \\
(0.153)\end{array}$ & $\begin{array}{l}0.321 * * \\
(0.150)\end{array}$ & $\begin{array}{l}0.298^{*} \\
(0.155)\end{array}$ & $\begin{array}{c}0.295^{* *} \\
(0.147)\end{array}$ & $\begin{array}{c}0.252 \\
(0.155)\end{array}$ & $\begin{array}{l}-0.171 \\
(1.095)\end{array}$ & $\begin{array}{l}0.0841 \\
(1.089)\end{array}$ \\
\hline $\begin{array}{c}Q_{i} * \tilde{t}_{g} \\
\text { (Indirect Effect) }\end{array}$ & $\begin{array}{l}0.831^{* *} \\
(0.381)\end{array}$ & $\begin{array}{c}0.597 \\
(0.391)\end{array}$ & $\begin{array}{c}1.573 * * * \\
(0.431)\end{array}$ & $\begin{array}{c}1.342 * * * \\
(0.442)\end{array}$ & $\begin{array}{c}1.181 * * * \\
(0.437)\end{array}$ & $\begin{array}{l}0.939 * * \\
(0.447)\end{array}$ & $\begin{array}{c}5.863 \\
(4.455)\end{array}$ & $\begin{array}{c}6.460 \\
(4.973)\end{array}$ \\
\hline Observations & 17,724 & 16,638 & 10,567 & 10,009 & 9,005 & 8,545 & 1,562 & 1,464 \\
\hline R-squared & 0.658 & 0.662 & 0.517 & 0.525 & 0.537 & 0.546 & 0.424 & 0.424 \\
\hline \multicolumn{9}{|c|}{ High and Upper Middle Income LAC Countries } \\
\hline $\begin{array}{c}\ln \left(Q_{i}\right) * t_{g} \\
\text { (Direct Effect) }\end{array}$ & $\begin{array}{c}0.610^{* * *} \\
(0.194)\end{array}$ & $\begin{array}{c}0.493 * * \\
(0.216)\end{array}$ & $\begin{array}{c}0.459^{* *} \\
(0.211)\end{array}$ & $\begin{array}{c}0.355 \\
(0.239)\end{array}$ & $\begin{array}{c}0.546^{* * *} \\
(0.209)\end{array}$ & $\begin{array}{l}0.453 * * \\
(0.230)\end{array}$ & $\begin{array}{c}-1.964 * * \\
(0.931)\end{array}$ & $\begin{array}{l}-1.979^{*} \\
(1.063)\end{array}$ \\
\hline $\begin{array}{c}\ln \left(Q_{i}\right) * \tilde{t}_{g} \\
\text { (Indirect Effect) }\end{array}$ & $\begin{array}{c}0.405 \\
(0.386)\end{array}$ & $\begin{array}{l}0.979 * * \\
(0.434)\end{array}$ & $\begin{array}{c}1.142 * * * \\
(0.432)\end{array}$ & $\begin{array}{c}1.698 * * * \\
(0.492)\end{array}$ & $\begin{array}{c}0.694 \\
(0.438)\end{array}$ & $\begin{array}{l}1.260^{* *} \\
(0.496)\end{array}$ & $\begin{array}{c}4.692 \\
(4.132)\end{array}$ & $\begin{array}{c}4.900 \\
(4.804)\end{array}$ \\
\hline Observations & 16,567 & 15,482 & 9,645 & 9,088 & 8,183 & 7,721 & 1,462 & 1,367 \\
\hline R-squared & 0.659 & 0.663 & 0.526 & 0.533 & 0.541 & 0.549 & 0.469 & 0.474 \\
\hline $\begin{array}{l}\text { Dependent variable } \\
\text { geography features } \\
\text { final product } g \text { on ti } \\
\text { good g on time. A p } \\
\text { comparative advant }\end{array}$ & $\begin{array}{l}3 \text { aggregate } \\
\text { tries) used } \\
\text { lereas, the } i \\
\text { coefficient } \\
\text { roducts tha }\end{array}$ & $\begin{array}{l}\text { olume. All } \\
\text { scribed in I } \\
\text { ffect of refo } \\
\text { riable } Q_{i} * \\
\text { e sensitive i }\end{array}$ & $\begin{array}{l}\text { essions cont } \\
\text { ach. The di } \\
\text { the sector } g \\
\text { es a compar } \\
\text { obust stand }\end{array}$ & $\begin{array}{l}\text { her factor } \\
t \text { of reform } \\
\text { rom the im } \\
\text { antage in } p \\
\text { in parenth }\end{array}$ & $\begin{array}{l}\text { s, and incl } \\
\text { tor } g \text { come } \\
t \text { in its abil } \\
\text { at are time } \\
<0.01, * *\end{array}$ & $\begin{array}{l}\text { ry and pro } \\
\text { improver } \\
\text { ess the inte } \\
\text { whereas, } \\
p<0.1 \text {. }\end{array}$ & $\begin{array}{l}\text { effects. In } \\
\text { untry i’s ab } \\
\text { nputs j use } \\
\text { coefficient }\end{array}$ & $\begin{array}{l}\text { S (physical } \\
\text { ransport its } \\
\text { production } \\
g \text { implies a }\end{array}$ \\
\hline
\end{tabular}


24. As expected, Table 4 shows that the coefficient estimates for the variables of interest, $Q_{i} * t_{g}$ and $Q_{i} * \tilde{t}_{g}$, are positive and statistically significant for this restricted sample of Latin American countries across the first three product groups (all products, primary and processed goods, and processed goods only). Similar to the results for the entire world in Table 3, the indirect effects arising through input-output linkages are larger than the direct effects of reforms for this restricted sample. In fact, the indirect effects of reforms seem particularly stronger for processed goods than for primary goods. I find that Latin American countries (with higher levels of income or LPI) that can transport goods on time export relatively more in industries for which timely delivery of inputs is of a higher concern. Similar to the results in Table 3 for the world, Latin American countries do not seem to have significant trade effects of transportation infrastructure reforms on the primary goods. In fact, Latin American countries with higher levels of LPI or income seem to have either no significant effect or a contraction effect, respectively, on the existing primary goods exports with a rise in transportation quality. This prompts us to study the effects of transportation infrastructure reforms on the export participation in addition to the existing export volume (See Chapter 2).

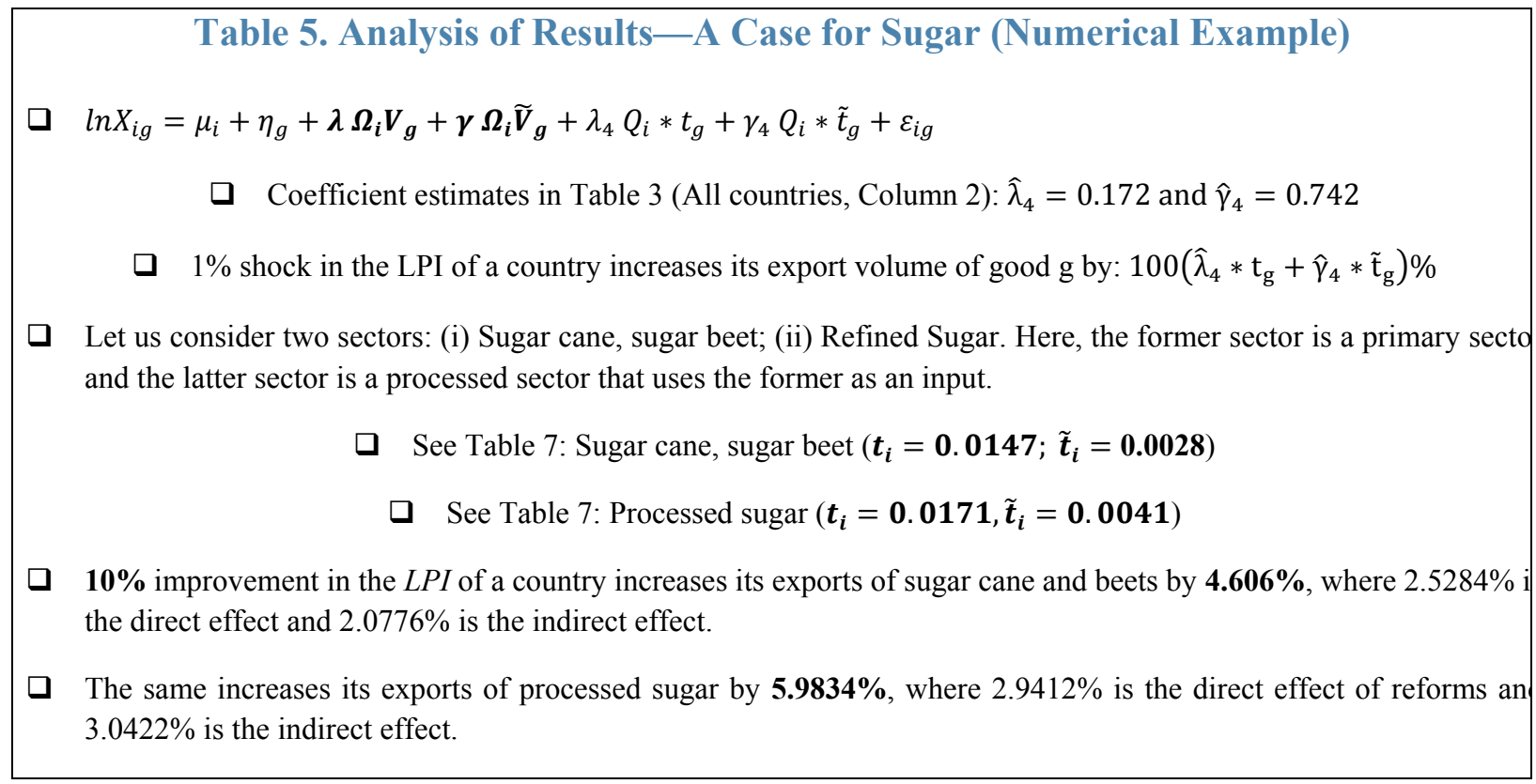


Table 6a. Effect of a 10\% Improvement in the LPI Level of an Average Country (World)

Sector

Grains, Seeds and Fibers

Textile and Wearing Apparel

Processed Food

Vegetables, Fruits and Nuts

Other Crops

Leather and Wood Prods

Extraction

Motor, Parts and Transport

Machinery and Electronics

Meat and Livestock

Paper, Metal and Mineral Prods

Chemicals and Ferrous Metals
Direct Time Cost

(in ad-valorem terms)
0.0145
0.7082
0.3515
0.6148
0.839
0.4069
0.2088
1.1412
0.9269
0.2342
1.1397
1.1628

Indirect Time Cost

(in ad-valorem terms)

$\begin{array}{ll}0.1941 & 1.4652 \\ 0.078 & 1.7969 \\ 0.2258 & 2.2800 \\ 0.189 & 2.4598 \\ 0.1606 & 2.6347 \\ 0.3029 & 2.9474 \\ 0.374 & 3.1342 \\ 0.1852 & 3.3370 \\ 0.3233 & 3.9932 \\ 0.5537 & 4.5113 \\ 0.3649 & 4.6678 \\ 2.1097 & 17.6540\end{array}$

\section{Export Volume}

Change (\%)

1.4652
1.7969
2.2800
2.4598
2.6347
2.9474
3.1342
3.3370
3.9932
4.5113
4.6678
7.6540

17.6540

\section{Figure 8a. Effect of a 10\% Improvement in the LPI Level of an Average Country} (World)

\section{Effect of a $10 \%$ Improvement in the LPI Level of an Average Country}

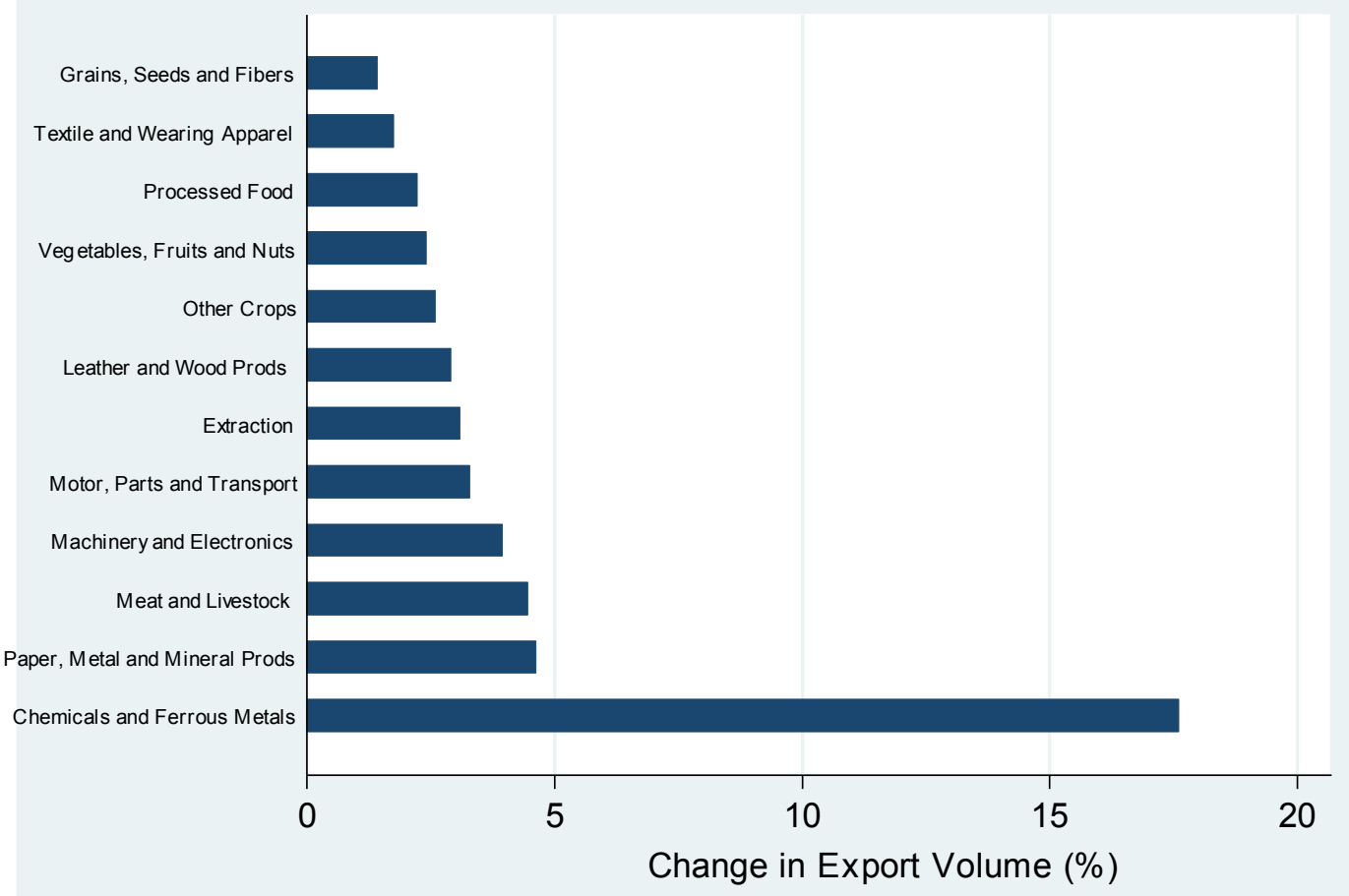




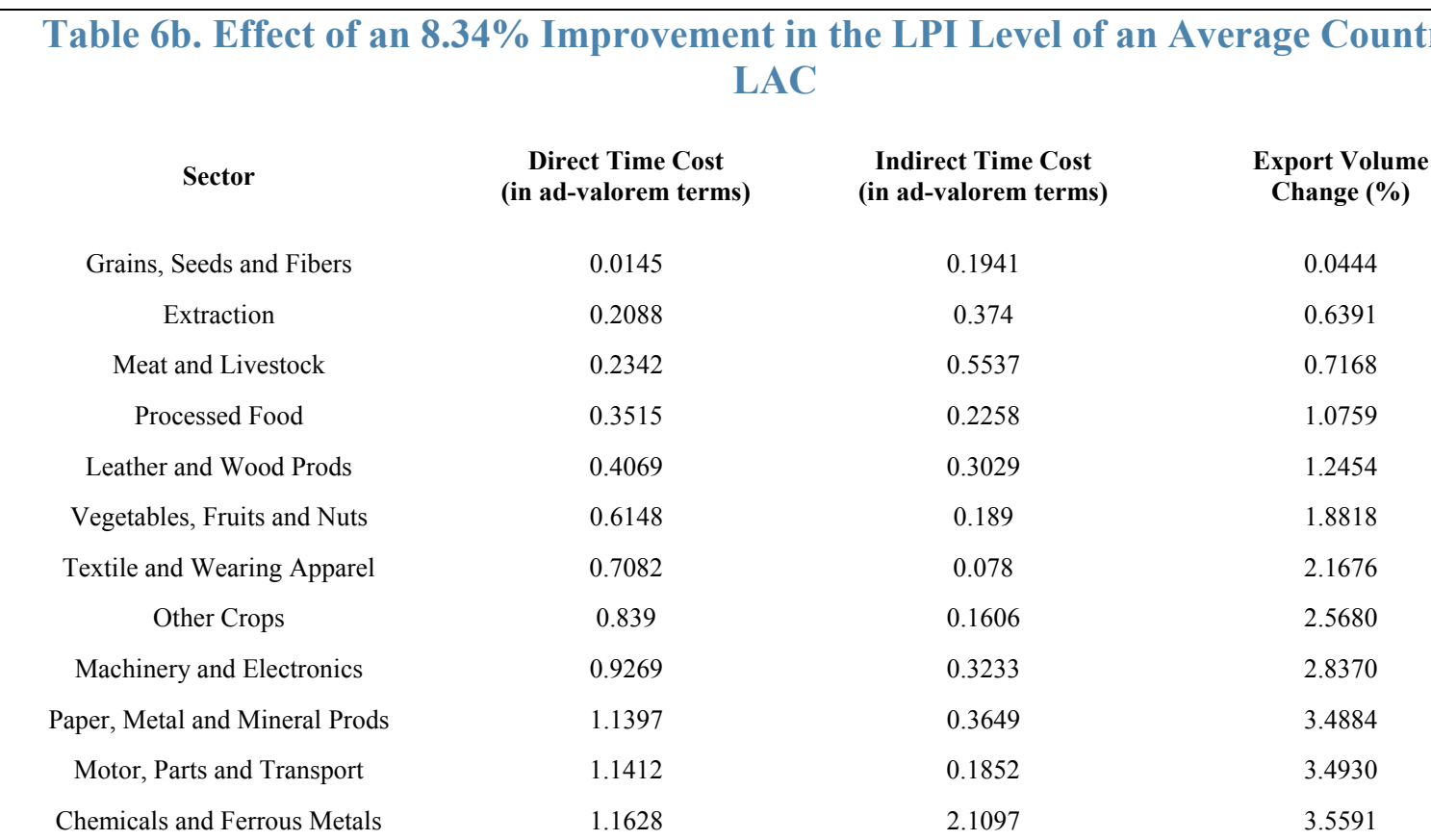

Policy Shock: We introduce an $8.34 \%$ improvement in the quality of transportation infrastructure (LPI) of Latin America. This conservative policy shock will increase the 2016 LPI level of Latin America (2.665) to the 2016 LPI level of Middle East and North Africa (2.887), which has the next best level of infrastructure quality after Latin American region. We use the coefficients obtained in Table 3 for LAC (Column 2). Data Source: 2013 aggregate export volume come from UN Comtrade Database. 2016 LPI comes from World Bank's LPI Database. Direct measures of time sensitivity come from Hummels and Schaur (2013), and the indirect measure of time sensitivity is as computed in this paper. I aggregate these measures of time sensitivity to the GTAP product level listed in this table for this policy analysis.

\section{Figure 8b. Effect of an $\mathbf{8 . 3 4 \%}$ Improvement in the LPI of Latin America}

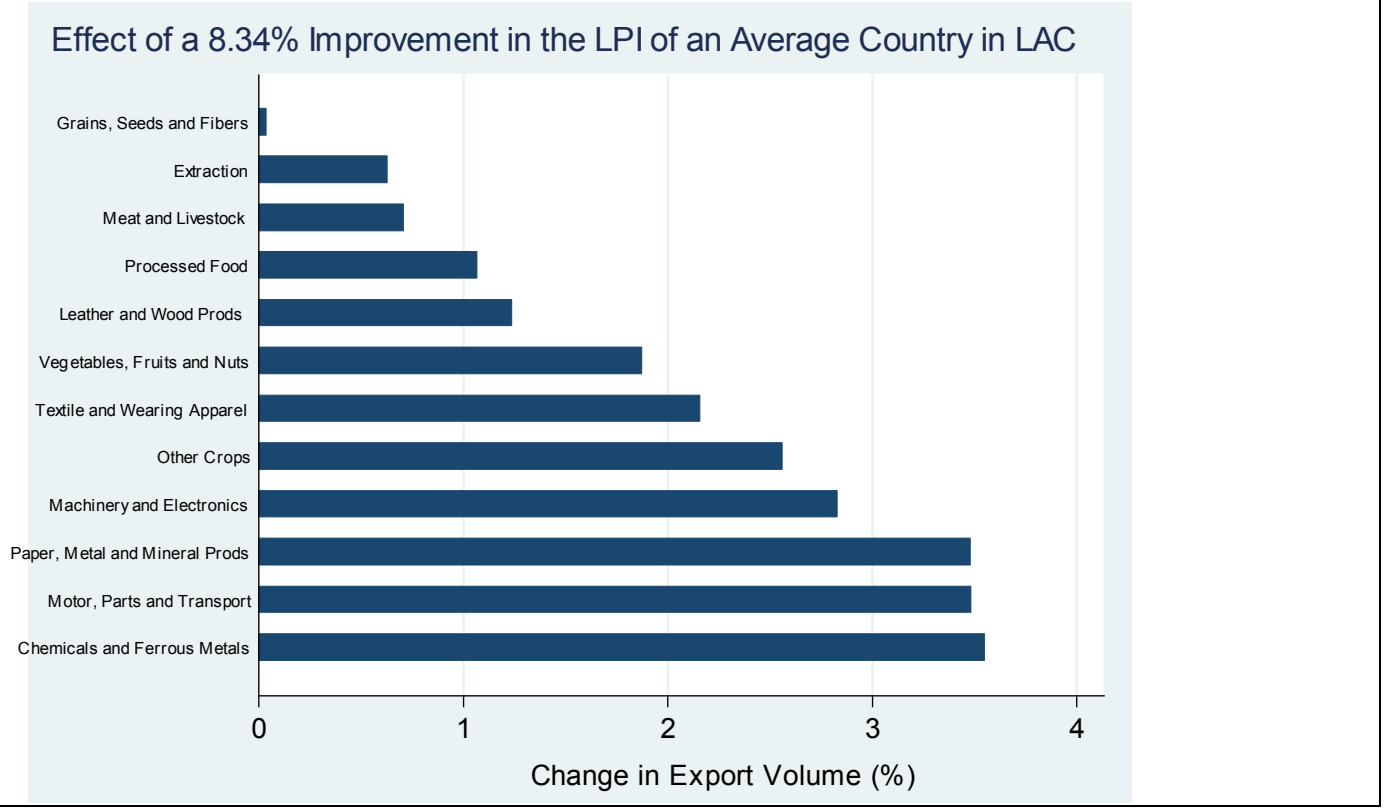

\section{CInternational Monetary Fund. Not for Redistribution}




\begin{tabular}{|c|c|c|c|}
\hline \multicolumn{4}{|c|}{$\begin{array}{l}\text { Table 6c. Effect of an 8.34\% Improvement in the LPI of an Average Country in LAC } \\
\text { (High and Upper Middle Income Countries in Latin America) }\end{array}$} \\
\hline Sector & $\begin{array}{c}\text { Direct Time Cost } \\
\text { (in ad-valorem terms) }\end{array}$ & $\begin{array}{l}\text { Indirect Time Cost } \\
\text { (in ad-valorem terms) }\end{array}$ & $\begin{array}{l}\text { Export Volume } \\
\text { Change }(\%)\end{array}$ \\
\hline Grains, Seeds and Fibers & 0.0145 & 0.1941 & 1.6444 \\
\hline Processed Food & 0.3515 & 0.2258 & 3.2889 \\
\hline Textile and Wearing Apparel & 0.7082 & 0.078 & 3.5487 \\
\hline Extraction & 0.2088 & 0.374 & 3.9122 \\
\hline Vegetables, Fruits and Nuts & 0.6148 & 0.189 & 4.0710 \\
\hline Leather and Wood Prods & 0.4069 & 0.3029 & 4.1462 \\
\hline Other Crops & 0.839 & 0.1606 & 4.7609 \\
\hline Meat and Livestock & 0.2342 & 0.5537 & 5.4838 \\
\hline Motor, Parts and Transport & 1.1412 & 0.1852 & 6.2043 \\
\hline Machinery and Electronics & 0.9269 & 0.3233 & 6.4508 \\
\hline Paper, Metal and Mineral Prods & 1.1397 & 0.3649 & 7.6654 \\
\hline Chemicals and Ferrous Metals & 1.1628 & 2.1097 & 22.0064 \\
\hline \multicolumn{4}{|c|}{$\begin{array}{l}\text { Policy Shock: We introduce } 8.34 \% \text { improvement in the quality of transportation infrastructure (LPI) of Latin America. This conservative } \\
\text { policy shock will increase the } 2016 \text { LPI level of Latin America (2.665) to the } 2016 \text { LPI level of Middle East and North Africa (2.887), which } \\
\text { has the next best level of infrastructure quality after Latin American region. We use the coefficients obtained in Table } 5 \text { (High and Upper } \\
\text { Middle Income Countries) for LAC (Column 2). }\end{array}$} \\
\hline
\end{tabular}

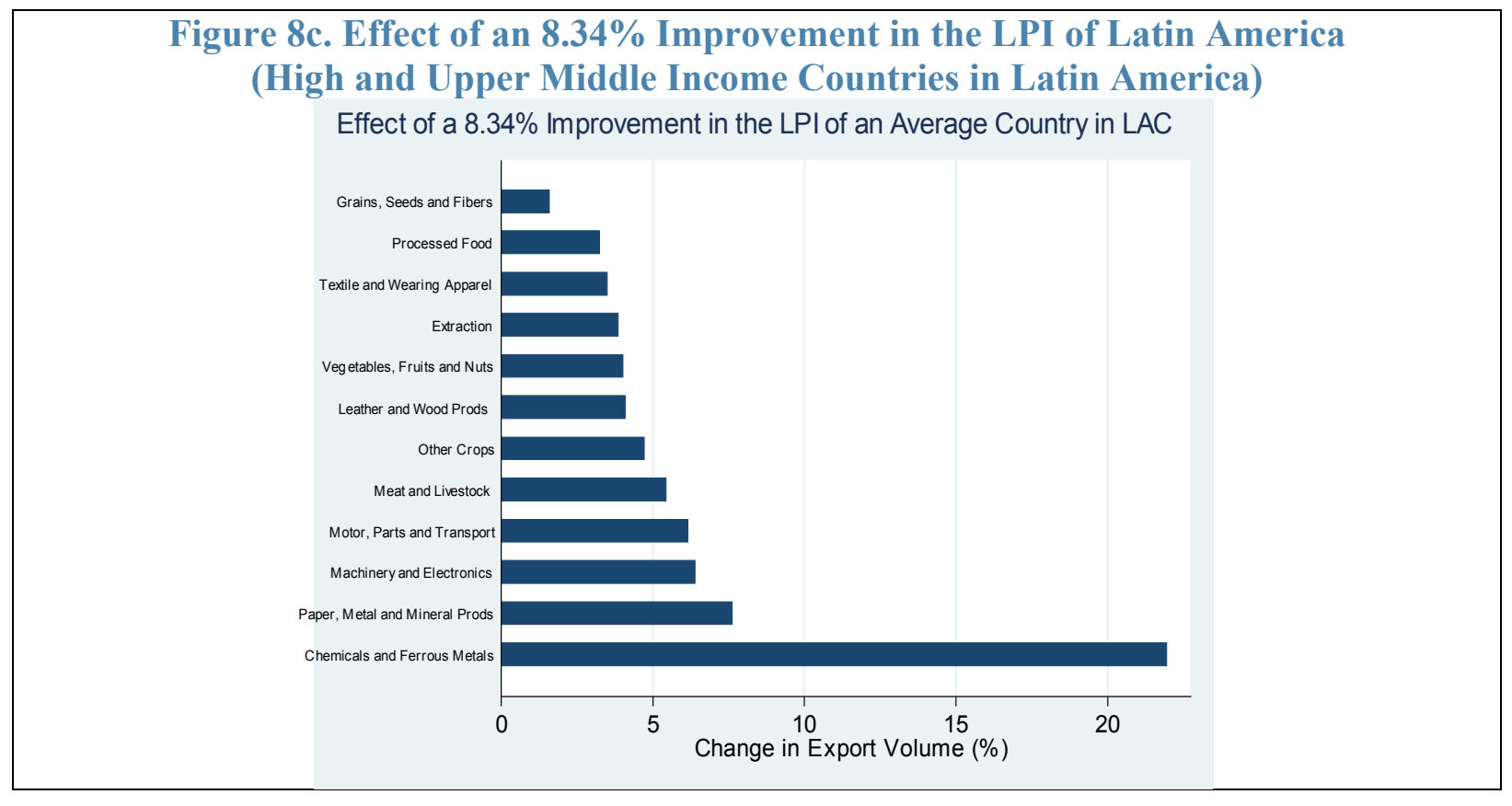




\section{ROBUSTNESS CHECK}

\section{A. Magnification Effects}

25. Hummels and Hillberry (2002) emphasize the importance of addressing the colocation between upstream and downstream firms in the presence of trade costs that can lead to magnification effects on trade due to input-output linkages. Many papers in this literature show that firms face a trade-off between time costs and freight costs, and the value of time in the management of production chains provides an incentive to upstream and downstream firms to cluster around each other. In particular, Hummels and Hillberry (2002) suggest that industrial expenditure on intermediate inputs are correlated with the trade frictions, and omitting it from the estimating equation causes the trade barrier variables to pick up both the direct and indirect effects of frictions. In the context of this paper, what good and how much of that good a country produces and exports depends on what upstream activity or intermediate inputs and how much of these inputs are available locally because of the presence of time cost in transporting the intermediate inputs from upstream to downstream industries. For instance, Nepal is a major exporter of finished tea products, because tea farming is done abundantly in Nepal. The availability of upstream activity or intermediate inputs in a region drives up the downstream industrial demand for these locally available intermediate inputs, and thus, downstream production and exports in that region. Hence, I now control for this omitted variable in the following way.

For each industry $g$ in country $i$, the industrial demand for locally available intermediate inputs is given by:

$$
\text { Ind. Demand } i g=\sum_{j}\left(\theta_{j}^{g i} * Y_{i j}\right) \text {, where }
$$

$\theta_{j}^{g i}$ is the share of input $j$ in the total intermediate inputs used in industry $g$ in country $i$, and $Y_{i j}$ is the industrial output of input $j$ in country $i$.

Here, the downstream industrial demand for intermediate inputs in a region is a function of the quantity of upstream industrial output available in that region. Clearly, the industrial demand for intermediate inputs drives up the downstream production and exports. Moreover, what upstream activity is present in a region determines the downstream industrial demand for these locally available intermediate inputs, which directly depends on the time costs in accessing these intermediate inputs $j$, i.e. Ind. Demand $i g$ and $Q_{i} * \tilde{t}_{g}$ are correlated. Therefore, in the estimating equation used in this paper, it is important to control for industrial demand for locally available intermediate inputs. Hence, I now estimate the following:

\section{Baseline Co-location Equation:}

$\ln X_{i g}=\gamma_{0}+\mu_{i}+\eta_{g}+\lambda \boldsymbol{\Omega}_{\boldsymbol{i}} \boldsymbol{V}_{\boldsymbol{g}}+\boldsymbol{\gamma} \boldsymbol{\Omega}_{\boldsymbol{i}} \widetilde{\boldsymbol{V}}_{\boldsymbol{g}}+\lambda_{4} Q_{i} * t_{g}+\gamma_{4} Q_{i} * \tilde{t}_{g}+$ Ind. Demand ${ }_{i g}+$ $\varepsilon_{i g}$, where 


$$
\text { Ind. } \text { Demand }_{i g}=\sum_{j}\left(\theta_{j}^{g i} * Y_{i j}\right)
$$

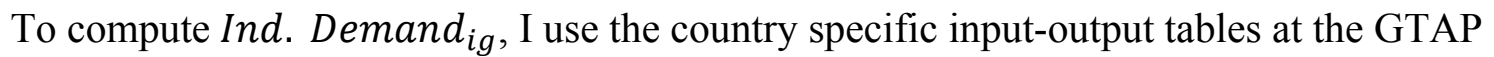
sectoral level obtained from the GTAP database, version 9. This is the best available data for country-specific input output tables to my knowledge in terms of the maximum number of countries and sectors covered.

Before reporting the regression results for the above co-location equation, I present below the aggregated direct and indirect time sensitivity measures at the GTAP sectoral level in Table 7. We see that the time sensitivity measures are larger for sectors that undergo larger number of production stages. As argued earlier, this is because goods that are heavily integrated in the global production chains face larger indirect time costs. I wish to exploit this variation in product characteristic and the variation in regions in terms of quality of transportation infrastructure to explain the comparative advantage pattern between primary and processed goods.

Table 7. Measures of Direct and Indirect Time Sensitivity at the GTAP Sectoral Level

\begin{tabular}{|c|c|c|c|c|c|c|}
\hline GTAP & Code & Product Description & Sector & Sector Description & Direct TS (ad-valorem) & Indirect TS (ad-valorem) \\
\hline 1 & $\mathrm{pdr}$ & Paddy rice & 1 & GrainsFibers & 0.000508 & 0.0023333 \\
\hline 2 & wht & Wheat & 1 & GrainsFibers & 0 & 0.0043389 \\
\hline 3 & gro & Cereal grains nec & 1 & GrainsFibers & 0 & 0.0043389 \\
\hline 7 & $\mathrm{pfb}$ & Plant-based fibers & 1 & GrainsFibers & 0 & 0 \\
\hline 5 & osd & Oil seeds & 1 & GrainsFibers & 0.0087671 & 0.0023488 \\
\hline 4 & $v_{-} f$ & Vegetables, fruit, nuts & 2 & VegFruitNuts & 0.0235516 & 0.0027757 \\
\hline 6 & c_b & Sugar cane, sugar beet & 2 & VegFruitNuts & 0.0146637 & 0.0028 \\
\hline 8 & ocr & Crops nec & 2 & VegFruitNuts & 0.0166813 & 0.0022188 \\
\hline 9 & ctl & Cattle,sheep,goats,horses & 3 & Livestock & 0.0039411 & 0.0058517 \\
\hline 10 & oap & Animal products nec & 3 & Livestock & 0.0641075 & 0.0091291 \\
\hline 12 & wol & Wool, silk-worm cocoons & 3 & Livestock & 0.0045795 & 0.006483 \\
\hline 13 & frs & Forestry & 4 & Extraction & 0.0100386 & 0.0027292 \\
\hline 14 & fsh & Fishing & 4 & Extraction & 0.0070245 & 0.0056364 \\
\hline 15 & coa & Coal & 4 & Extraction & 0 & 0.0028288 \\
\hline 16 & oil & Oil & 4 & Extraction & 0 & 0.0020674 \\
\hline 17 & gas & Gas & 4 & Extraction & 0 & 0.0033242 \\
\hline 18 & omn & Minerals nec & 4 & Extraction & 0.0338036 & 0.0033682 \\
\hline 19 & $\mathrm{cmt}$ & Meat: cattle,sheep,goats,horse & 5 & MeatProds & 0.0032495 & 0.0114224 \\
\hline 20 & omt & Meat products nec & 5 & MeatProds & 0.0081828 & 0.0090872 \\
\hline 21 & vol & Vegetable oils and fats & 6 & ProcFood & 0.0105094 & 0.0045419 \\
\hline 22 & mil & Dairy products & 6 & ProcFood & 0.0112525 & 0.0022267 \\
\hline 23 & pcr & Processed rice & 6 & ProcFood & 0.000508 & 0.0024685 \\
\hline 24 & sgr & Sugar & 6 & ProcFood & 0.0170757 & 0.0041382 \\
\hline 25 & ofd & Food products nec & 6 & ProcFood & 0.0193944 & 0.0048296 \\
\hline 26 & b_t & Beverages and tobacco products & 6 & ProcFood & 0.0072561 & 0.0023842 \\
\hline
\end{tabular}




\begin{tabular}{|c|c|c|c|c|c|c|}
\hline \multicolumn{7}{|c|}{$\begin{array}{l}\text { Table 7. Measures of Direct and Indirect Time Sensitivity at the GTAP Sectoral Level } \\
\text { (Concluded) }\end{array}$} \\
\hline GTAP & Code & Product Description & Sector & Sector Description & Direct TS (ad-valorem) & Indirect TS (ad-valorem) \\
\hline 27 & tex & Textiles & 7 & TextWapp & 0.0101978 & 0.0015954 \\
\hline 28 & wap & Wearing apparel & 7 & TextWapp & 0.0079326 & 0.0032562 \\
\hline 29 & lea & Leather products & 7 & TextWapp & 0.00853 & 0.0042618 \\
\hline 30 & lum & Wood products & 8 & WoodMin & 0.0095866 & 0.0028819 \\
\hline 34 & $\mathrm{nmm}$ & Mineral products nec & 8 & WoodMin & 0.0182981 & 0.0027991 \\
\hline 31 & ppp & Paper products, publishing & 9 & OtherMnfes & 0.0156981 & 0.0044909 \\
\hline 37 & fmp & Metal products & 9 & OtherMnfcs & 0.0136803 & 0.0045098 \\
\hline 36 & $\mathrm{nfm}$ & Metals nec & 9 & OtherMnfcs & 0.022802 & 0.0055999 \\
\hline 42 & omf & Manufactures nec & 9 & OtherMnfes & 0.0165249 & 0.0049502 \\
\hline 32 & p_c & Petroleum, coal products & 9 & OtherMnfcs & 0.0111507 & 0.007832 \\
\hline 33 & crp & Chemical, rubber, plastic prods & 10 & ChemFe & 0.0233705 & 0.0081167 \\
\hline 35 & i_s & Ferrous Metals & 10 & ChemFe & 0.0152934 & 0.0171485 \\
\hline 38 & mvh & Motor vehicles and parts & 11 & MotorTrans & 0.021681 & 0.0037575 \\
\hline 39 & otn & Transport equipment nec & 11 & MotorTrans & 0.0118743 & 0.0034971 \\
\hline 40 & ele & Electronic equipment & 12 & MachElec & 0.0100862 & 0.003296 \\
\hline 41 & ome & Machinery and equipment nec & 12 & MachElec & 0.0103674 & 0.0031691 \\
\hline 31 & ppp & Paper products, publishing & 9 & OtherMnfcs & 0.0156981 & 0.0044909 \\
\hline 37 & fmp & Metal products & 9 & OtherMnfes & 0.0136803 & 0.0045098 \\
\hline 36 & $\mathrm{nfm}$ & Metals nec & 9 & OtherMnfcs & 0.022802 & 0.0055999 \\
\hline 42 & omf & Manufactures nec & 9 & OtherMnfcs & 0.0165249 & 0.0049502 \\
\hline 32 & p_c & Petroleum, coal products & 9 & OtherMnfcs & 0.0111507 & 0.007832 \\
\hline 33 & crp & Chemical, rubber, plastic prods & 10 & ChemFe & 0.0233705 & 0.0081167 \\
\hline 35 & i_s & Ferrous Metals & 10 & ChemFe & 0.0152934 & 0.0171485 \\
\hline 38 & mvh & Motor vehicles and parts & 11 & MotorTrans & 0.021681 & 0.0037575 \\
\hline 39 & otn & Transport equipment nec & 11 & MotorTrans & 0.0118743 & 0.0034971 \\
\hline 40 & ele & Electronic equipment & 12 & MachElec & 0.0100862 & 0.003296 \\
\hline 41 & ome & Machinery and equipment nec & 12 & MachElec & 0.0103674 & 0.0031691 \\
\hline 31 & ppp & Paper products, publishing & 9 & OtherMnfcs & 0.0156981 & 0.0044909 \\
\hline 37 & fmp & Metal products & 9 & OtherMnfcs & 0.0136803 & 0.0045098 \\
\hline 36 & $\mathrm{nfm}$ & Metals nec & 9 & OtherMnfcs & 0.022802 & 0.0055999 \\
\hline 42 & omf & Manufactures nec & 9 & OtherMnfcs & 0.0165249 & 0.0049502 \\
\hline 32 & p_c & Petroleum, coal products & 9 & OtherMnfcs & 0.0111507 & 0.007832 \\
\hline 33 & crp & Chemical, rubber, plastic prods & 10 & ChemFe & 0.0233705 & 0.0081167 \\
\hline 35 & $\mathrm{i}_{-} \mathrm{s}$ & Ferrous Metals & 10 & ChemFe & 0.0152934 & 0.0171485 \\
\hline 38 & mvh & Motor vehicles and parts & 11 & MotorTrans & 0.021681 & 0.0037575 \\
\hline
\end{tabular}

\section{CInternational Monetary Fund. Not for Redistribution}




\section{B. Endogeneity between Upstream and Downstream Production}

26. In addition to controlling for the reverse causality issue between the trade and transportation infrastructure using physical geography features of a country (denoted by $T_{i}$ below) as instruments for the quality of transportation infrastructure, I wish to control for the reverse causality issue between downstream production and the industrial demand for intermediate inputs. Clearly, the causality runs in the other direction as well. If the trade prospect of a downstream industry is high, thereby leading to high downstream production, the industrial demand for locally available intermediate inputs, and therefore, the industrial output of the locally available upstream industries will also rise. That is, the upstream and downstream productions are jointly determined. Moreover, what downstream activity is present in a region also determines the quantity of locally available intermediate inputs in the presence of such indirect time costs. To control for this endogeneity issue, I use the interaction of the exogenously given natural resources endowment of country $i$ and the natural resource intensity of the bundle of intermediate inputs used in the production of the upstream industry as an instrument for the availability of the upstream input. That is, I use

$$
\left(\mathrm{R}_{\mathrm{i}} * \tilde{r}_{j}\right) \text { as an instrument for } \mathrm{Y}_{\mathrm{ij}} \text {. }
$$

I define the instrument for Ind. Demand $i g$ as follows:

$$
\text { Dem. Instr }{ }_{i g}=\sum_{j}\left(\theta_{j}^{i g} *\left(R_{i} * \widetilde{r}_{J}\right)\right)
$$

The correlation between Ind. Demand Ig $_{\text {and Dem. Instr }}$ ig is 0.43 .

I now estimate the following IV regression:

\section{Control for Co-location and Reverse Causality Issues:}

Instrumental Variable Approach:

- First Stage:

$$
\begin{aligned}
& Q_{i} * t_{g}=\mu_{i}+\eta_{g}+\boldsymbol{\imath} \boldsymbol{\Omega}_{\boldsymbol{i}} \boldsymbol{V}_{\boldsymbol{g}}+\boldsymbol{\alpha} \boldsymbol{\Omega}_{\boldsymbol{i}} \widetilde{\boldsymbol{V}}_{\boldsymbol{g}}+\iota_{4} \boldsymbol{T}_{\boldsymbol{i}} * t_{g}+\alpha_{4} \boldsymbol{T}_{\boldsymbol{i}} * \tilde{t}_{g}+\sigma_{1} \text { Dem.Instr }{ }_{i g}+v_{i g} \\
& Q_{i} * \tilde{t}_{g}=\mu_{i}+\eta_{\boldsymbol{g}}+\boldsymbol{\kappa} \boldsymbol{\Omega}_{\boldsymbol{i}} \boldsymbol{V}_{\boldsymbol{g}}+\boldsymbol{\beta} \boldsymbol{\Omega}_{\boldsymbol{i}} \widetilde{\boldsymbol{V}}_{\boldsymbol{g}}+\kappa_{4} \boldsymbol{T}_{\boldsymbol{i}} * t_{g}+\beta_{4} \boldsymbol{T}_{\boldsymbol{i}} * \tilde{t}_{g}+\sigma_{2} \text { Dem.Instr } r_{i g}+\delta_{i g}
\end{aligned}
$$

Ind. Demand

$$
\begin{aligned}
& =\mu_{i}+\eta_{g}+\boldsymbol{\pi} \boldsymbol{\Omega}_{\boldsymbol{i}} \boldsymbol{V}_{\boldsymbol{g}}+\boldsymbol{\rho} \boldsymbol{\Omega}_{\boldsymbol{i}} \widetilde{\boldsymbol{V}}_{\boldsymbol{g}}+\pi_{4} \boldsymbol{T}_{\boldsymbol{i}} * t_{g}+\rho_{4} \boldsymbol{T}_{\boldsymbol{i}} * \tilde{t}_{g}+\sigma_{3} \text { Dem. Instr } \\
& +\omega_{i g}
\end{aligned}
$$

- Second Stage:

$$
\ln X_{i g}=\mu_{i}+\eta_{g}+\boldsymbol{\lambda} \boldsymbol{\Omega}_{\boldsymbol{i}} \boldsymbol{V}_{\boldsymbol{g}}+\boldsymbol{\gamma} \boldsymbol{\Omega}_{\boldsymbol{i}} \widetilde{\boldsymbol{V}}_{\boldsymbol{g}}+\lambda_{4} \widehat{Q_{\imath} * t_{g}}+\gamma_{4} \widehat{Q_{\imath} * \tilde{t}_{g}}+\varsigma \text { Ind. } \widehat{\text { Demand }}{ }_{\imath g}+\varepsilon_{i g}
$$




\begin{tabular}{|c|c|c|c|c|c|c|c|c|}
\hline \multicolumn{9}{|c|}{ Table 8: Control for Magnification Effects } \\
\hline \multicolumn{9}{|c|}{ All Countries } \\
\hline \multirow{3}{*}{ VARIABLES } & \multirow{2}{*}{\multicolumn{2}{|c|}{$\begin{array}{l}\text { All Products } \\
\text { Export Volume }\end{array}$}} & \multirow{2}{*}{\multicolumn{2}{|c|}{$\begin{array}{l}\text { Primary \& Processed } \\
\text { Export Volume }\end{array}$}} & \multirow{2}{*}{\multicolumn{2}{|c|}{$\begin{array}{l}\text { Processed Goods } \\
\text { Export Volume }\end{array}$}} & \multirow{2}{*}{\multicolumn{2}{|c|}{$\begin{array}{l}\text { Primary Goods } \\
\text { Export Volume }\end{array}$}} \\
\hline & & & & & & & & \\
\hline & OLS & IV & OLS & IV & OLS & IV & OLS & IV \\
\hline $\begin{array}{c}Q_{i} * t_{g} \\
\text { (Direct Effect) }\end{array}$ & $\begin{array}{c}0.0989 * * * \\
(0.0271)\end{array}$ & $\begin{array}{l}0.187 * * * \\
(0.0660)\end{array}$ & $\begin{array}{l}0.137 * * * \\
(0.0303)\end{array}$ & $\begin{array}{l}0.200^{* * *} \\
(0.0723)\end{array}$ & $\begin{array}{c}0.146^{* * *} \\
(0.0313)\end{array}$ & $\begin{array}{l}0.171 * * \\
(0.0710)\end{array}$ & $\begin{array}{c}-0.272^{* *} \\
(0.135)\end{array}$ & $\begin{array}{l}-0.181 \\
(0.307)\end{array}$ \\
\hline $\begin{array}{c}Q_{i} * \tilde{t}_{g} \\
\text { (Indirect Effect) }\end{array}$ & $\begin{array}{c}0.194 * * * \\
(0.0593)\end{array}$ & $\begin{array}{r}0.333^{* *} \\
(0.139)\end{array}$ & $\begin{array}{c}0.379 * * * \\
(0.0664)\end{array}$ & $\begin{array}{c}0.795 * * * \\
(0.154)\end{array}$ & $\begin{array}{c}0.291 * * * \\
(0.0680)\end{array}$ & $\begin{array}{c}0.588 * * * \\
(0.158)\end{array}$ & $\begin{array}{l}-0.305 \\
(0.575)\end{array}$ & $\begin{array}{l}-0.605 \\
(1.834)\end{array}$ \\
\hline Industrial Dem & $\begin{array}{l}0.472 * * * \\
(0.0275)\end{array}$ & $\begin{array}{c}0.152 \\
(0.169)\end{array}$ & $\begin{array}{l}0.455^{* * *} \\
(0.0389)\end{array}$ & $\begin{array}{r}0.472 * * \\
(0.201)\end{array}$ & $\begin{array}{r}0.487 * * * \\
(0.0423)\end{array}$ & $\begin{array}{r}0.426^{* *} \\
(0.214)\end{array}$ & $\begin{array}{r}0.256^{* *} \\
(0.118)\end{array}$ & $\begin{array}{l}-0.931 \\
(0.826)\end{array}$ \\
\hline $1^{\text {st }}$ Stg F-stat & & $473.92 * * *$ & & $616.57 * * *$ & & $358.68^{* * *}$ & & $170.29 * * *$ \\
\hline $1^{\text {st }}$ Stg F-stat & & $5251.85^{* * *}$ & & $3194.70 * * *$ & & $2893.21 * * *$ & & $109.86^{* * *}$ \\
\hline $1^{\text {st }}$ Stg F-stat & & $175.21 * * *$ & & $258.72 * * *$ & & $162.34 * * *$ & & $30.59 * * *$ \\
\hline Observations & 104,362 & 43,792 & 64,615 & 26,915 & 54,436 & 22,729 & 10,179 & 4,186 \\
\hline R-squared & 0.672 & 0.671 & 0.548 & 0.547 & 0.572 & 0.576 & 0.453 & 0.426 \\
\hline
\end{tabular}


27. Table 8 shows that when I include Ind. Demand $_{i g}$ in the baseline equation to control for the co-location effects, the magnitude of the variable of interest, $\boldsymbol{Q}_{\boldsymbol{i}} * \tilde{\boldsymbol{t}}_{\boldsymbol{g}}$, gets smaller indicating that we do face the problem of co-location in our estimation.

However, the coefficient estimates of interest are still significantly positive and consistent to our previous conclusions. In particular, a country that has a higher ability to transport goods on time has a comparative advantage in those industries that place a higher value on the timely delivery of their inputs. Also, even after addressing the magnification effects, the indirect effects of reforms are still larger than the direct effects across the first three product groups.

\section{Columns 3 and 4 present the results separately for the processed and primary} goods. This exercise confirms that the comparative advantage pattern in products that value timely delivery of intermediate inputs is stronger for processed goods than for the primary goods even after controlling for the magnification effects.

29. The results for the second stage of the IV estimation for different product groups are also reported in Table 8. Along with the above mentioned instrument for industrial demand for intermediates, I use physical geography features of a country as instruments for the quality of transportation infrastructure of the country. Again, the IV estimations are consistent with the OLS estimates. Overall, timeliness in transporting intermediate inputs is a relatively more important source of comparative advantage for processed goods than for primary goods.

Table 9. Analysis of Results_-A Case for Sugar (Numerical Example)

$\ln X_{i g}=\mu_{i}+\eta_{g}+\lambda \boldsymbol{\Omega}_{\boldsymbol{i}} \boldsymbol{V}_{\boldsymbol{g}}+\boldsymbol{\gamma} \boldsymbol{\Omega}_{\boldsymbol{i}} \widetilde{\boldsymbol{V}}_{\boldsymbol{g}}+\lambda_{4} Q_{i} * t_{g}+\gamma_{4} Q_{i} * \tilde{t}_{g}+\varepsilon_{i g}$

a Coefficient estimates in Table 3 (All countries, Column 2): $\hat{\lambda}_{4}=0.187$ and $\hat{\gamma}_{4}=0.333$

$1 \%$ shock in the LPI of a country increases its export volume of good $g$ by: $100\left(\hat{\lambda}_{4} * t_{g}+\hat{\gamma}_{4} * \tilde{t}_{\mathrm{g}}\right) \%$

Let us consider two sectors: (i) Sugar cane, sugar beet; (ii) Refined Sugar. Here, the former sector is a primary sector and the latter sector is a processed sector that uses the former as an input.

See Table 7: Sugar cane, sugar beet $\left(\boldsymbol{t}_{\boldsymbol{i}}=\mathbf{0 . 0 1 4 7} ; \tilde{\boldsymbol{t}}_{\boldsymbol{i}}=\mathbf{0 . 0 0 2 8}\right)$

- See Table 7: Processed sugar $\left(\boldsymbol{t}_{\boldsymbol{i}}=\mathbf{0 . 0 1 7 1}, \tilde{\boldsymbol{t}}_{\boldsymbol{i}}=\mathbf{0 . 0 0 4 1}\right)$

口 $\mathbf{1 0} \%$ improvement in the $L P I$ of a country increases its exports of sugar cane and beets by $\mathbf{3 . 6 8 1 3 \%}$, where $2.7489 \%$ is the direct effect and $0.9324 \%$ is the indirect effect.

- The same increases its exports of processed sugar by $\mathbf{4 . 5 6 3 \%}$, where $3.1977 \%$ is the direct effect of reforms an $1.3653 \%$ is the indirect effect. 


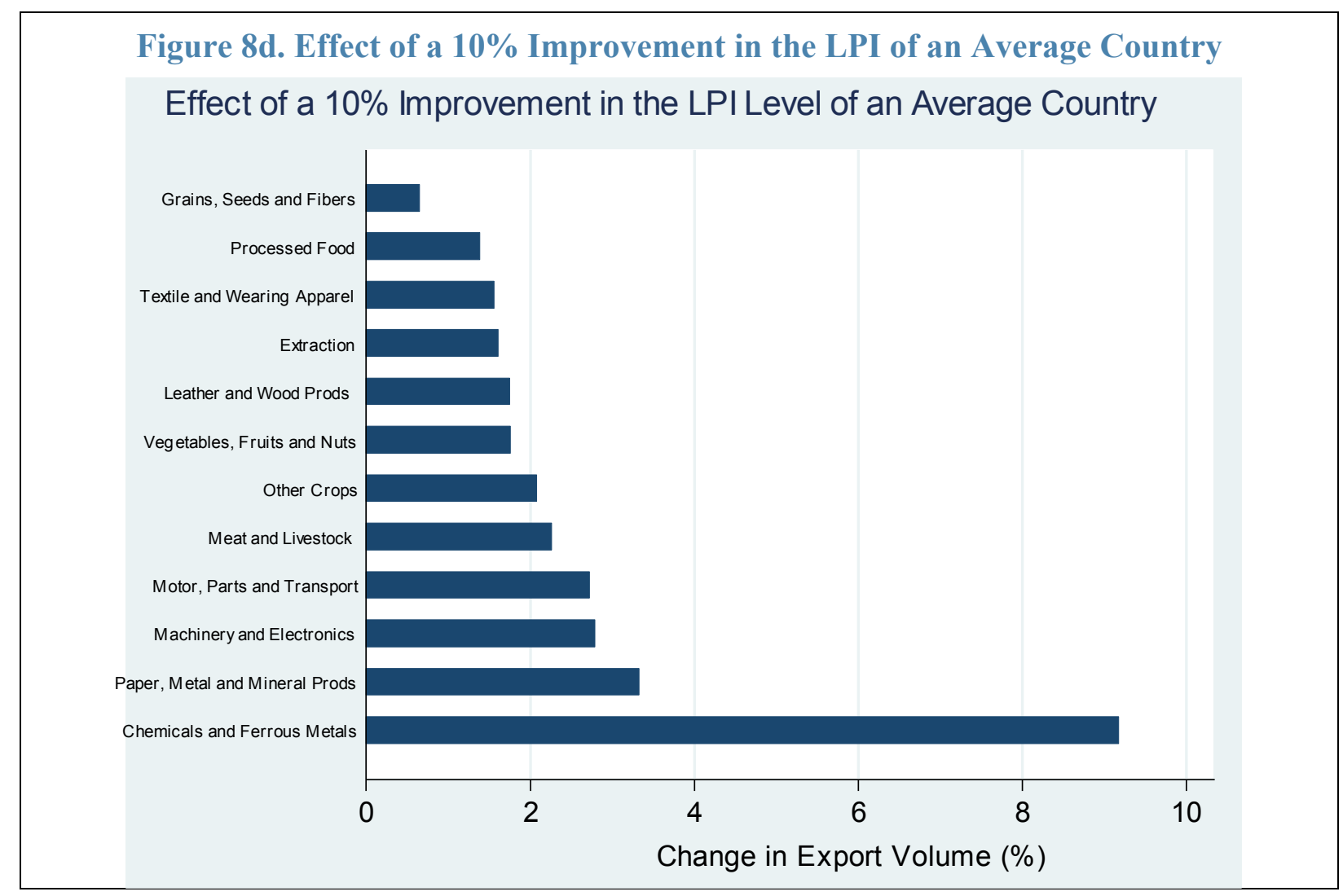

\section{Robust Measure for Indirect Time Sensitivity}

30. It might be a concern that the measure of indirect time cost constructed in this paper includes the direct time cost in addition to the time cost in accessing other inputs, leading to double counting, and thereby overestimating the indirect effect of transportation infrastructure reforms. Hence, for the robustness check, I now use a robust measure for indirect time cost, which excludes the diagonal elements of the input-output matrix so that it corrects this issue. In particular,

$$
\tilde{t}_{g}^{\prime}=\sum_{j \neq g}\left[\theta_{j}^{g} * t_{j}\right]
$$

31. The results using this second measure of indirect time cost, denoted as $\tilde{t}_{g}{ }^{\prime}$, is presented below in Table 10. We can see that this robust measure of indirect time cost does not change the main conclusions of this paper. However, the direct effects now seem more important than reported earlier for both primary and processed commodities, as expected. Also, the magnitude of the indirect effects is smaller than the baseline results. However, this exercise confirms that our main results are consistent even while using this conservative measure of indirect time cost. Thus, I conclude that the indirect effects of transportation infrastructure reforms are larger than the direct effects across many robustness checks. As concluded earlier, any country that has a higher quality of transportation infrastructure has a comparative advantage in products that value timely delivery of inputs. Overall, timeliness in 
trade drives the comparative advantage pattern in processed goods, which mainly comes from the indirect channel.

\begin{tabular}{|c|c|c|c|c|c|c|c|c|}
\hline \multicolumn{9}{|c|}{$\begin{array}{c}\text { Table 10. Robust Measure of Indirect Time Intensity } \\
\text { All Countries }\end{array}$} \\
\hline & \multicolumn{2}{|c|}{ All Products } & \multicolumn{2}{|c|}{ Primary \& Processed } & \multicolumn{2}{|c|}{ Processed Goods } & \multicolumn{2}{|c|}{ Primary Goods } \\
\hline \multirow[t]{2}{*}{ VARIABLES } & \multicolumn{2}{|c|}{ Export Volume } & \multicolumn{2}{|c|}{ Export Volume } & \multicolumn{2}{|c|}{ Export Volume } & \multicolumn{2}{|c|}{ Export Volume } \\
\hline & OLS & IV & OLS & IV & OLS & IV & OLS & IV \\
\hline$Q_{i} * t_{g}$ & $0.106^{* * *}$ & $0.197 * * *$ & $0.131 * * *$ & $0.187 * *$ & $0.137 * * *$ & $0.162 * *$ & $-0.406 * * *$ & -0.174 \\
\hline (Direct Effect) & $(0.0274)$ & $(0.0681)$ & $(0.0307)$ & $(0.0733)$ & $(0.0314)$ & $(0.0716)$ & $(0.152)$ & $(0.340)$ \\
\hline$Q_{i} * \tilde{t}_{g}^{\prime}$ & $0.153 * * *$ & $0.298 * * *$ & $0.259 * * *$ & $0.461 * * *$ & $0.306^{* * *}$ & $0.497 * * *$ & $-0.529 * * *$ & -0.512 \\
\hline (Indirect Effect) & $(0.0371)$ & $(0.0888)$ & $(0.0414)$ & $(0.100)$ & $(0.0432)$ & $(0.108)$ & $(0.143)$ & $(0.333)$ \\
\hline Industrial Dem & $0.482 * * *$ & $0.303^{*}$ & $0.478 * * *$ & $0.967 * * *$ & $0.516^{* * *}$ & $0.857 * * *$ & 0.0662 & 0.183 \\
\hline & $(0.0277)$ & $(0.157)$ & $(0.0395)$ & $(0.211)$ & $(0.0424)$ & $(0.218)$ & $(0.161)$ & $(0.881)$ \\
\hline $1^{\text {st }}$ Stg F-stat & & $668.00 * * *$ & & $866.35 * * *$ & & $611.84 * * *$ & & $150.63 * * *$ \\
\hline $1^{\text {st }}$ Stg F-stat & & $1457.54 * * *$ & & $1145.17 * * *$ & & $1015.90 * * *$ & & $284.33 * * *$ \\
\hline $1^{\text {st }}$ Stg F-stat & & $175.11^{* * *}$ & & $239.14 * * *$ & & $165.42 * * *$ & & $26.11 * * *$ \\
\hline Observations & 102,605 & 43,082 & 62,849 & 26,199 & 54,328 & 22,688 & 8,521 & 3,511 \\
\hline R-squared & 0.673 & 0.674 & 0.547 & 0.548 & 0.572 & 0.574 & 0.434 & 0.434 \\
\hline
\end{tabular}

\section{Dropping the Extraction Sector}

\section{This robustness check analyzes the previous result by dropping the mining} sector from the analysis. It might be a concern that the time sensitivity of the extraction sector is significantly different compared to the rest of the primary goods commodities, and including the extraction sector within the primary goods commodities might underestimate the importance of timeliness in trade for the primary goods commodities. Hence, I now run the above regression without including the extraction sector in this analysis. The results are presented below in Table 11. We can see that dropping the mining sector does not change the result of this paper. However, the direct effects seem more important than reported earlier for the sample containing all products. 


\begin{tabular}{|c|c|c|c|c|c|c|c|c|}
\hline \multicolumn{9}{|c|}{$\begin{array}{c}\text { Table 11. Dropping the Extraction Sector } \\
\text { All Countries }\end{array}$} \\
\hline \multirow{3}{*}{ VARIABLES } & \multicolumn{2}{|c|}{ All Products } & \multicolumn{2}{|c|}{ Primary \& Processed } & \multicolumn{2}{|c|}{ Processed Goods } & \multicolumn{2}{|c|}{ Primary Goods } \\
\hline & \multicolumn{2}{|c|}{ Export Volume } & \multicolumn{2}{|c|}{ Export Volume } & \multicolumn{2}{|c|}{ Export Volume } & \multicolumn{2}{|c|}{ Export Volume } \\
\hline & OLS & IV & OLS & IV & OLS & IV & OLS & IV \\
\hline $\begin{array}{c}Q_{i} * t_{g} \\
(\text { Direct Effect) }\end{array}$ & $\begin{array}{l}0.118^{* * *} \\
(0.0277)\end{array}$ & $\begin{array}{l}0.206^{* * *} \\
(0.0699)\end{array}$ & $\begin{array}{l}0.147 * * * \\
(0.0315)\end{array}$ & $\begin{array}{l}0.198 * * * \\
(0.0763)\end{array}$ & $\begin{array}{l}0.137 * * * \\
(0.0314)\end{array}$ & $\begin{array}{l}0.162 * * \\
(0.0715)\end{array}$ & $\begin{array}{c}-0.574 * * * \\
(0.221)\end{array}$ & $\begin{array}{l}-0.241 \\
(0.583)\end{array}$ \\
\hline $\begin{array}{c}\quad Q_{i} * \tilde{t}_{g}{ }^{\prime} \\
\text { (Indirect Effect) }\end{array}$ & $\begin{array}{l}0.144 * * * \\
(0.0370)\end{array}$ & $\begin{array}{l}0.275^{* * *} \\
(0.0891)\end{array}$ & $\begin{array}{l}0.248 * * * \\
(0.0413)\end{array}$ & $\begin{array}{c}0.439 * * * \\
(0.101)\end{array}$ & $\begin{array}{c}0.303 * * * \\
(0.0432)\end{array}$ & $\begin{array}{c}0.497 * * * \\
(0.108)\end{array}$ & $\begin{array}{c}-0.507 * * * \\
(0.143)\end{array}$ & $\begin{array}{l}-0.434 \\
(0.333)\end{array}$ \\
\hline Industrial Dem & $\begin{array}{c}0.489 * * * \\
(0.0275)\end{array}$ & $\begin{array}{l}0.270^{*} \\
(0.153)\end{array}$ & $\begin{array}{c}0.490 * * * \\
(0.0391)\end{array}$ & $\begin{array}{c}0.958 * * * \\
(0.203)\end{array}$ & $\begin{array}{c}0.516^{* * *} \\
(0.0424)\end{array}$ & $\begin{array}{c}0.864 * * * \\
(0.216)\end{array}$ & $\begin{array}{l}0.0872 \\
(0.174)\end{array}$ & $\begin{array}{c}0.529 \\
(1.058)\end{array}$ \\
\hline $1^{\text {st }}$ Stg F-stat & & $456.61 * * *$ & & $573.67 * * *$ & & $351.32 * * *$ & & $136.50 * * *$ \\
\hline $1^{\text {st }}$ Stg F-stat & & $48.79 * * *$ & & $39.84 * * *$ & & $44.01 * * *$ & & $6.53^{* * *}$ \\
\hline $1^{\text {st }}$ Stg F-stat & & $172.57 * * *$ & & $256.78 * * *$ & & $162.85^{* * *}$ & & $29.03 * * *$ \\
\hline Observations & 100,670 & 42,272 & 60,918 & 25,391 & 54,283 & 22,669 & 6,635 & 2,722 \\
\hline R-squared & 0.679 & 0.680 & 0.555 & 0.555 & 0.573 & 0.575 & 0.459 & 0.446 \\
\hline
\end{tabular}

33. Therefore, from all the robustness checks carried out in this paper, I conclude that the IV regression results in Table 3 , is a well-specified model that can be used to explain the comparative advantage in processed goods arising from the indirect effects of timeliness in trade. The results reported in Table 3 could be a slight over-estimation of importance of timeliness in determining the comparative advantage between primary and processed goods via the indirect channel based on various robustness checks, but I believe that the baseline IV estimation analysis reported in Table 3 is consistent across many robustness checks. Hence, using the IV estimations in Table 3, I conclude that, on average, a 10 percent improvement in the transportation infrastructure quality of a country leads to approximately 5.9 percent increment in the export volume of primary goods and 12.8 percent increment in that of processed goods.

\section{CONCLUSION}

34. In this paper, I emphasize the role of a country's ability to transport goods on time in explaining the trade pattern between primary and processed goods. In particular, to explain the comparative advantage in processed goods for countries with better quality of transportation infrastructure, I focus on the interaction between the intensity with which producers demand for the timely delivery of their intermediate inputs and countries' quality of transportation infrastructure. This paper shows that a country's ability to access intermediate inputs on time can become an important source of comparative advantage in processed goods. Through this paper, I add to the literature by focusing on the value of time in the management of production chain, which explains the trade pattern between primary and processed goods. That 
is, I assess a clear effect of the cost of time delays incurred while transporting intermediate inputs from upstream to downstream industries on the trade pattern.

35. This is achieved, first, by the construction of a measure for how intensively producers demand for the timely delivery of their bundle of intermediate inputs following the procedure carried out in Nunn (2007) in constructing a measure for contract intensity across industries. Such a measure for indirect time cost across industries is computed as the share weighted average of input specific direct time cost (computed in Hummels and Schaur, 2013), where the direct time cost is the ad-valorem tariff equivalent of consumers' willingness to pay more for a good to be delivered one day earlier.

36. I test the effects of indirect time costs on the pattern of trade following the empirical specification as in Nunn (2007). The estimating equation explains export volumes by the interactions of a product characteristic with a country characteristic. Physical geography features of a country, such as the mean elevation and distance from the coast, are used as instruments of the quality of transportation infrastructure to address the endogeneity between trade and investment in the transportation infrastructure. Further, the paper controls for the magnification effects (endogeneity between availability of upstream activities in a region and the downstream production and exports) due to the correlation between downstream industrial demand for intermediate inputs and the time cost in accessing the inputs. In addition, a robust measure of indirect time sensitivity across products is constructed by eliminating the diagonal elements of the input-output matrix to address double counting. This work is then applied to the Latin American region to examine the effects of timeliness in trade on the comparative advantage pattern in processed goods.

\section{I find that countries that can transport goods on time export relatively more in} industries for which timely delivery of their inputs is of a higher concern. And, this comparative advantage pattern is stronger for processed goods than for primary goods, because processed goods face higher time costs in accessing their inputs than primary goods do. In other words, timeliness in accessing the intermediate inputs is an important source of comparative advantage for processed goods arising from the value of time in the management of production chain. Further, I find that both the direct and indirect effects of transportation infrastructure reforms are positive and significant for the sample containing all products, both primary and processed goods, and processed goods only. However, the indirect effects are larger than the direct effects. On the other hand, I do not find consistently significant effect of timeliness in trade for primary commodities. Further, the indirect effects of transportation infrastructure reforms for processed goods are significantly and consistently larger than those for primary goods across various empirical specifications. Hence, timeliness in trade is particularly important for processed goods. I conclude that, on average, a 10 percent improvement in the transportation infrastructure quality of a country leads to approximately 5.9 percent increment in the export volume of primary goods and 12.8 percent increment in that of processed goods.

\section{EXtension to THE Firm Heterogeneity CGE ModeL}

38. Moving forward, I examine the effect of an improvement in the quality of transportation infrastructure, i.e. logistics performance index, on the trade volume of existing exporters (intensive margin), the number of new varieties being traded (extensive 
margin) and industry productivity. For this policy analysis, we use the newly developed GTAP firm-heterogeneity model (Akgul et al., 2015), which explicitly models consumers' loveof-variety, endogenous changes in the number of varieties, and trade-induced productivity changes. We use this model primarily because it enables us to examine the effect of transportation infrastructure reforms on the trade pattern between primary and processed goods arising through two channels. In particular, improvement in timeliness in trade leads to both the technical change in reducing the fixed trade costs and the technical change in reducing the variable trade costs, which increase the number of firms entering into the export market and the export volume, respectively. Further, we investigate if these effects of trade facilitation are significantly different for processed goods industry than for primary goods industry.

\section{Trade facilitation in the standard GTAP model is incorporated as an efficiency} change in the use of factor inputs by considering its implications on the effective price and quantity of imports from an exporter (Hertel et al., 2001). In particular, a shock in the tradeaugmenting technology variable that reduced variable trade costs, AMS, affects the total imports from the exporter applying the reform via three distinct effects: substitution towards this exporter, expansion effect (less is required to obtain the same composite aggregate import), and the import substitution effect. This model is extended in Mirza (2010) to link the logistics performance index to the trade-augmenting technology variable, AMS, in order to analyze the effect of investments in trade facilitation related capital goods on trade. We extend this development, first by incorporating both the direct and indirect effects of improvement in logistics performance index on the trade-augmenting technical shifter, AMS. This informs us on the effects of trade facilitation on the variable trade cost. We then use the firm-heterogeneity model in GTAP to link the logistics performance index to the model variable for the technical change in fixed trade costs, AVAFS, in order to analyze the direct and indirect effects of trade facilitation on the fixed trade cost (selection or variety effects).

40. In order to compute the required shock on the technical change variables that will mimic the change in the logistics performance index, we need to further understand the effects of improved trade facilitation. On the one hand, trade facilitation affects variable trade costs via reductions in factor input requirements of production and leads to lower per unit costs. This has direct effects on prices. On the other hand, trade facilitation affects fixed export costs via reductions in factor input requirements devoted to customs procedures associated with exporting. As a result, it is important to isolate the variable and fixed costs components of the factor input usage efficiency. In order to achieve that, we econometrically specify the export volume based on a two-part model. The first stage estimates the effect of transportation infrastructure reforms on the probability that we observe a positive trade volume. This informs us on the fixed cost component of trade facilitation effects. The second stage estimates the effect of infrastructure reforms on the trade volume conditional on participation in trade. This informs us on the variable cost component of trade facilitation effects. Using this empirical information, we model the interaction of country-specific quality of transportation infrastructure and industry-specific time intensity as both the fixed cost to enter into the export market and the variable cost of trade. We then implement a targeted shock in logistics performance index in the firm-heterogeneity model in GTAP and compare the implications in the processed and primary goods industries with a focus on extensive margin effects for South and East Asia low income region. In addition to the impacts on export participation and composition, we analyze the effects on factor returns and reallocations, and decompose the welfare impacts. 


\section{REFERENCES}

Akgul, Z., N. B. Villoria, and T. W. Hertel (in review), "Introducing Firm Heterogeneity into the GTAP Model," Journal of Global Economic Analysis, Purdue University, 2015.

Akgul, Z., N. B. Villoria, and T. W. Hertel, 2015, "Theoretically-Consistent Parameterization of a Multi-sector Global Model with Heterogeneous Firms," GTAP Working Paper.

Abe, Kazutomo, and Wilson, John S., 2008, "Governance, Corruption, and Trade in the Asia Pacific Region,” (Washington: World Bank)

Albarran, P., R. Carrasco, and A. Holl, 2009, “Transport Infrastructure, Sunk Costs and Firm's Export Behavior," Working Paper 09-22, Universidad Carlos III de Madrid.

Balassa, B., 1965, "Trade Liberalization and Revealed Comparative Advantage," The Manchester School, 33(2), 99-123.

Baniya, S., 2015, "Effects of Time Cost on the Trade Pattern," Presented at the Midwest International Trade Conference (October), Pennsylvania State University.

Bloom, David E., David Canning, and Jaypee Sevilla, 2001, "Economic Growth and the Demographic Transition," NBER Working Paper No. 8685.

Blyde, J., 2012, "Paving the Road to Export: Assessing the Trade Impact of Road Quality," International Economic Journal, pp. 1-19.

Clark, X, D. Dollar, and A. Micco, 2004, "Port efficiency, maritime transport costs, and bilateral trade," Journal of Development Economics, 75, 417-450.

Cosar, A. K., and P. Fajgelbaum, 2013, "Internal Geography, International Trade, and Regional Specialization," NBER Working Paper No. 19697.

Cosar, A. K., and B. Demir, 2014, "Domestic Road Infrastructure and International Trade: Evidence from Turkey," Koç University-TUSIAD Economic Research Forum Working Papers 1406, Koc University-TUSIAD Economic Research Forum.

Deardorff, Alan V., 1980, "The General Validity of the Law of Comparative Advantage," Journal of Political Economy, University of Chicago Press, vol. 88(5) (October), pp. 94157.

Deardorff, Alan V., 2004, "Local Comparative Advantage: Trade Costs and the Pattern of Trade," manuscript, University of Michigan.

Dixit, Avinash, and Victor Norman, 1980, "The Gains from Free Trade," The Warwick Economics Research Paper Series (TWERPS) 173, University of Warwick, Department of Economics. 
Djankov, S., C. Freund, and C. S. Pham, 2010, "Trading on Time," The Review of Economics and Statistics, MIT Press, vol. 92(1) (February), pp.166-173.

Duranton, G., P. Morrow, and M. A. Turner, 2013, "Roads and Trade: Evidence from the U.S.," forthcoming, The Review of Economic Studies.

Escaith, Hubert, and Satoshi Inomata, 2013, "Geometry of Global Value Chains in East Asia: The Role of Industrial Networks and Trade Policies," GLOBAL VALUE CHAINS IN A CHANGING WORLD, 135-157 (Geneva: WTO Publications).

Evans, C. L., and J. Harrigan, 2005, "Distance, Time, and Specialization: Lean Retailing in General Equilibrium," American Economic Review, 95(1), pp. 292-313.

Francois, Joseph, and Miriam Manchin, 2007, "Institutions, Infrastructure, and Trade," IIDE Discussion Papers 20070401, Institute for International and Development Economics.

Frink, C., A. Mattoo, and I.C. Neagu, 2000, "Trade in International Maritime Service: How Much does Policy Matter?" mimeo (Washington: World Bank).

Gamberoni, Elisa, Rainer Lanz, and Roberta Piermartini, 2010, "Timeliness and contract enforceability in intermediate goods trade," Policy Research Working Paper Series 5482 (Washington: The World Bank).

Harrigan J., and A.J. Venables, 2004, "Timeliness, Trade and Agglomeration," NBER Working Paper No. 10404.

Hausman, W. H., L.L. Lee, and U. Subramanian, 2005, "Global Logistics Services, Supply Chain Metrics and Bilateral Trade Patterns," World Bank Policy Research Working Paper Series 3773 .

Hertel, T., T. Walmsley, and K. Ikatura, 2001, "Dynamic Effects of the "New Age" Free Trade Agreement between Japan and Singapore," Journal of Economic Integration, vol. 24, pp. 1019-1049.

Hummels, D., 2001, "Time as a Trade Barrier," GTAP Working Papers 1152, Center for Global Trade Analysis (Purdue University: Department of Agricultural Economics).

Hummels, D., J. Ishii, and K.-M. Yi, 2001, "The Nature and Growth of Vertical Specialization in World Trade," Journal of International Economics, 54, 75-96.

Hummels, D., P. Minor, M. Reisman, and E. Endean, 2007, Calculating Tariff Equivalents for Time in Trade. Arlington, VA: Nathan Associates Inc., for the United States Agency for International Development (USAID)

Hummels, David L., and Georg Schaur, 2013, "Time as a Trade Barrier," American Economic Review, vol. 103(7), pp. 2935-59. 
Ivanic, Maros, C. L. Mann, and John S. Wilson, 2006, “Aid for Trade Facilitation. Global Welfare Gains and Developing Countries," Draft.

Kremer, Michael, 1993, "The O-Ring Theory of Economic Development," The Quarterly Journal of Economics, vol. 108 (3), pp. 551-575 (Oxford University Press).

Li, Y., and J.S. Wilson, 2009, “Time as a Determinant of Comparative Advantage”, The World Bank Policy Research Working Paper Series 5128.

Limao, N., and Venables, 2001, "Infrastructure, Geographical Disadvantage, Transport Costs, and Trade," The World Bank Economic Review, vol. 15(3), pp. 451-479.

Minor, P., and M. Tsigas, 2008, "Impacts of Better Trade Facilitation in Developing Countries: Analysis with a New GTAP Database for the Value of Time in Trade," GTAP Resource Paper \#2762 (West Lafayette, Indiana: Purdue University).

Miranda, Rodrigo, and Rodrigo Wagner, 2015, "Bad Neighbors: Bordering Institutions Matter for Comparative (Dis) Advantage," Presented at the Midwest International Trade Conference (October), Pennsylvania State University.

Miroudot, S., R. Lanz and A. Ragoussis, 2009, "Trade in Intermediate Goods and Services," OECD Trade Policy Working Papers No. 93.

Mirza, Tasneem, 2009, "Infrastructure and Trade in Sub-Saharan Africa: Costs and Benefits of Reforms," GTAP Resource Paper \#3127 (West Lafayette, Indiana: Purdue University).

Nordas, H.K., 2003, "Vertical Specialization and the Quality of Infrastructure," ERSD Staff Working Paper No. 03-2003, World Trade Organization.

Nordas, Hildegunn, and Roberta Piermartini, 2004, "Infrastructure and Trade," World Trade Organization Staff Working Paper ERSD-2004-04.

Nunn, N., 2007, "Relationship-Specificity, Incomplete Contracts, and the Pattern of Trade," The Quarterly Journal of Economics, vol. 122(2), pp. 569-600.

Rabinowicz, Ewa, 1987, "Elements of agricultural trade policies: J.P. Houck. Macmillan, New York, 1986, 224 pp.,” Agricultural Economics, Blackwell, vol. 1(2) (June), pp. 191-192.

Ray, A., 1973, "Non-traded inputs and effective protection: A general equilibrium analysis," Journal of International Economics, vol. 3, issue 3, pp. 245-257.

Rousslang, D. J., and T. To (1993): "Domestic Trade and Transportation Costs as Barriers to International Trade," Canadian Journal of Economics, pp. 208-221.

Villar, Olga A., 2004, “The Effects of Transport Costs Revisited,” Documento de Traballo 0407. Universidade de Vigo. 
Volpe Martincus, C., and J. Blyde, 2013, "Shaky Roads and Trembling Exports: Assessing the Trade Effects of Domestic Infrastructure Using a Natural Experiment," Journal of International Economics, vol. 90(1), pp. 148-161.

Walkenhorst, P., and Tadashi Yasui, 2004, "Quantitative Assessment of the Benefits of Trade Facilitation,” International Trade 0401008, EconWPA.

Yeaple, S., and S. Golub, 2007, "International Productivity Differences, Infrastructure, and Comparative Advantage," Review of International Economics, vol.15(2), pp. 223-242. 


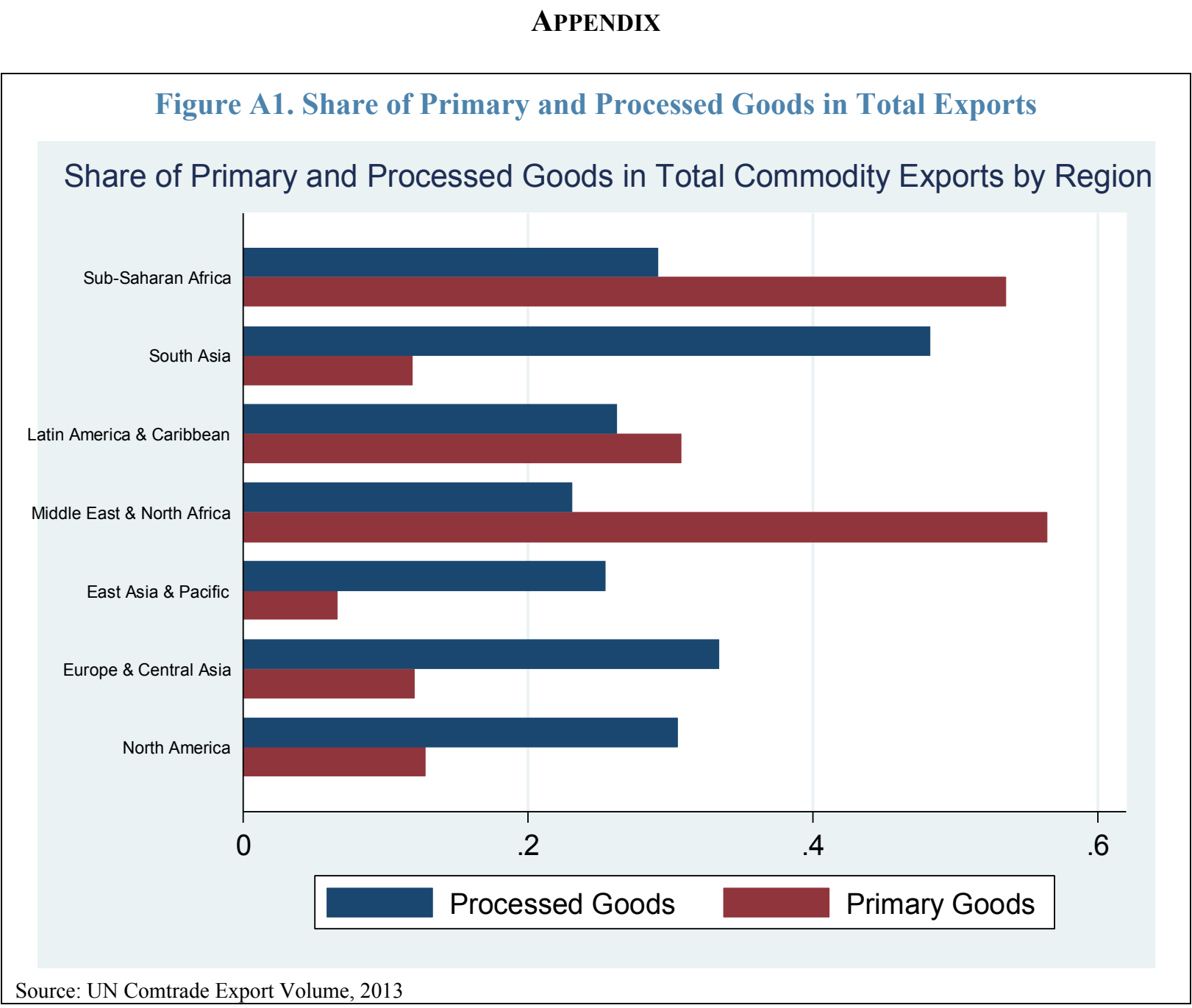

Sub-Saharan Africa (which has the least level of LPI compared to other regions) and the resource rich Middle East and North Africa mostly export primary goods, whereas, South Asia (with slightly higher LPI than Sub-Saharan Africa) mostly exports processed goods. With an LPI level around the world average, Latin America's export composition between primary and processed goods is relatively balanced, and the rest of the high LPI regions, including East Asia and Pacific, Europe and Central Asia, and North America export relatively less primary goods. In fact, the share of processed goods in total exports of these high LPI regions are not significantly larger either compared to other middle level LPI regions such as Middle East and North Africa, and Latin America. This indicates that these high LPI regions export relatively more in products that are at a higher level of the value chains. 
Figure A2. Country-Specific Weighted Average Direct Time Sensitivity of Products by LPI

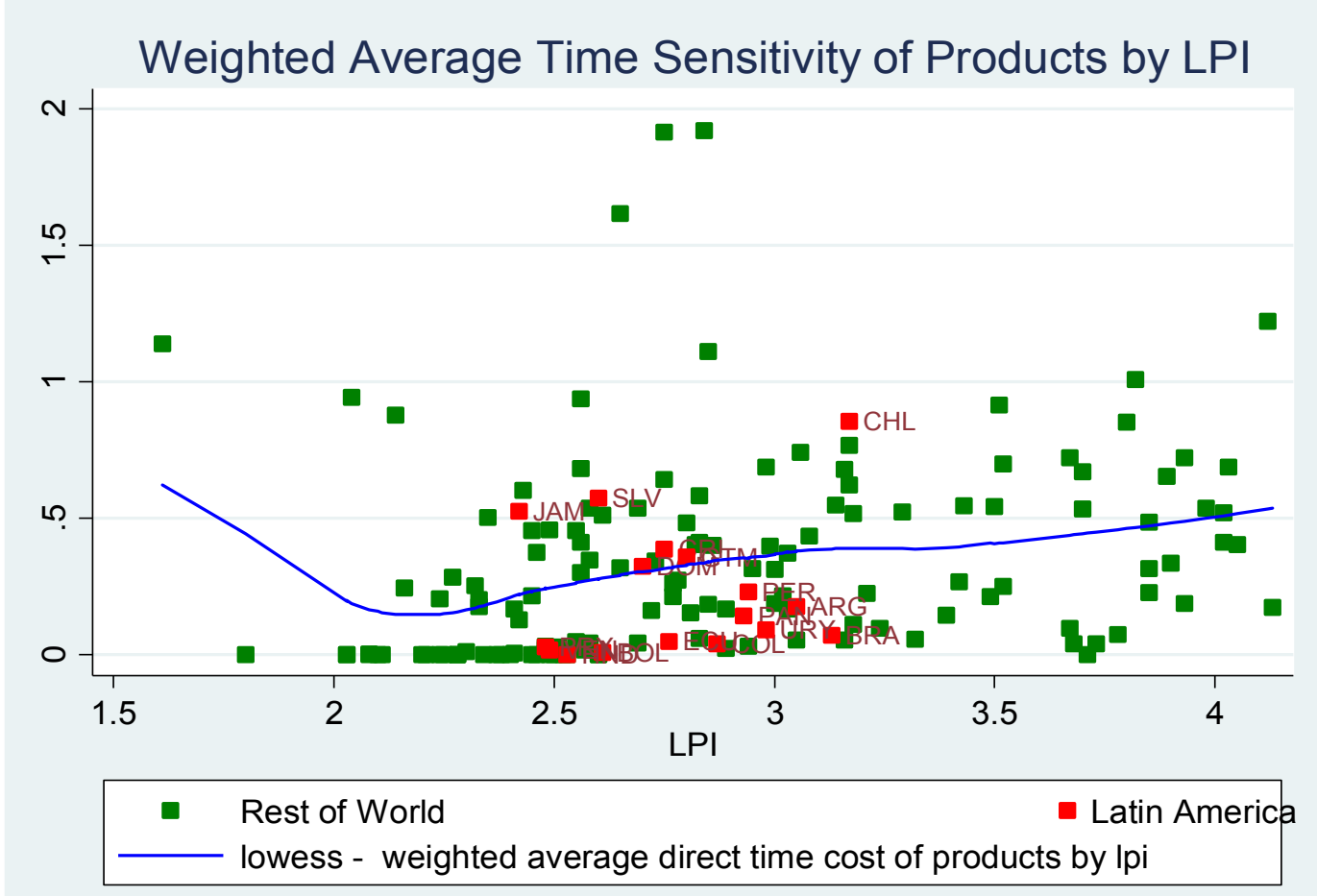

Weighted Average Heaviness of Products by LPI (w/o outliers)

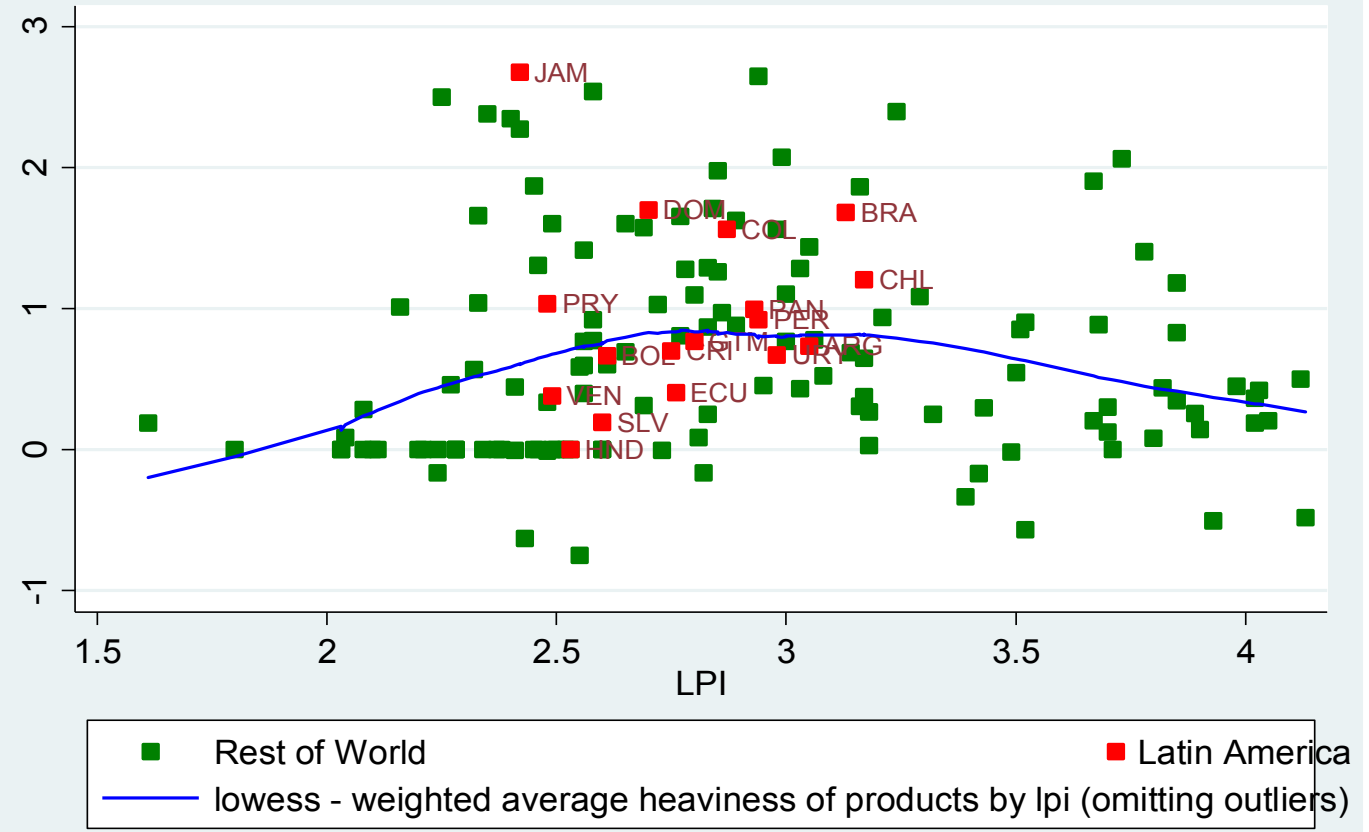

Source: Measure of direct time sensitivity of products are extracted from computations in Hummels and Schaur (2013). Weights are share of a product in the total exports of a country. The measure of heaviness is the logarithm of weight over value ratio obtained from the UN Comtrade database, 2013. 


\section{Additional Analysis on Latin America}

I examine additional impacts on the trade pattern arising due to improvement in timeliness in trade for Latin America. I particularly investigate if improvement in timeliness in trade due to transportation infrastructure reforms determine comparative advantage pattern in transportation intensive goods (such as heavy and upstream goods in addition to time-sensitive goods as examined earlier in the paper), and if such a comparative advantage pattern is stronger for processed goods than for primary goods. Below, I report the regression results and the analysis for Latin America, and how they compare to the rest of the world.

\begin{tabular}{|c|c|c|c|c|c|c|c|c|}
\hline \multirow{2}{*}{ VARIABLES } & \multicolumn{2}{|c|}{$\begin{array}{l}\text { All Products } \\
\text { Export Volume }\end{array}$} & \multicolumn{2}{|c|}{$\begin{array}{l}\text { Primary \& Processed } \\
\text { Export Volume }\end{array}$} & \multicolumn{2}{|c|}{$\begin{array}{l}\text { Processed Goods } \\
\text { Export Volume }\end{array}$} & \multicolumn{2}{|c|}{$\begin{array}{l}\text { Primary Goods } \\
\text { Export Volume }\end{array}$} \\
\hline & OLS & IV & OLS & IV & OLS & IV & OLS & IV \\
\hline \multicolumn{9}{|c|}{ ALL COUNTRIES } \\
\hline Heavy & $\begin{array}{l}0.724 * * * \\
(0.0127)\end{array}$ & $\begin{array}{c}1.193 * * * \\
(0.179)\end{array}$ & $\begin{array}{l}0.954 * * * \\
(0.0174)\end{array}$ & $\begin{array}{c}3.343^{* * *} \\
(0.568)\end{array}$ & $\begin{array}{l}0.931 * * * \\
(0.0184)\end{array}$ & $\begin{array}{c}3.199 * * * \\
(0.497)\end{array}$ & $\begin{array}{l}1.073 * * * \\
(0.0465)\end{array}$ & $\begin{array}{l}-0.915 \\
(1.568)\end{array}$ \\
\hline Upstreamness & $\begin{array}{c}0.0353 \\
(0.0987)\end{array}$ & $\begin{array}{c}0.960 * * * \\
(0.188)\end{array}$ & $\begin{array}{c}0.347^{* * *} \\
(0.129)\end{array}$ & $\begin{array}{c}1.453 * * * \\
(0.255)\end{array}$ & $\begin{array}{c}0.446^{* * *} \\
(0.139)\end{array}$ & $\begin{array}{c}2.071 * * * \\
(0.277)\end{array}$ & $\begin{array}{c}-0.832 * * \\
(0.366)\end{array}$ & $\begin{array}{c}-2.432 * * * \\
(0.696)\end{array}$ \\
\hline \multicolumn{9}{|c|}{ LATIN AMERICA } \\
\hline Heavy & $\begin{array}{c}0.827 * * * \\
(0.0257)\end{array}$ & $\begin{array}{c}1.265 * * * \\
(0.287)\end{array}$ & $\begin{array}{l}1.117 * * * \\
(0.0363)\end{array}$ & $\begin{array}{c}3.479 * * * \\
(0.770)\end{array}$ & $\begin{array}{l}1.103 * * * \\
(0.0384)\end{array}$ & $\begin{array}{c}2.600^{* * *} \\
(0.565)\end{array}$ & $\begin{array}{l}1.149 * * * \\
(0.0994)\end{array}$ & $\begin{array}{l}3.027^{* *} \\
(1.409)\end{array}$ \\
\hline Upstreamness & $\begin{array}{c}-0.00053 \\
(0.422)\end{array}$ & $\begin{array}{l}0.836^{*} \\
(0.481)\end{array}$ & $\begin{array}{c}0.654 \\
(0.565)\end{array}$ & $\begin{array}{l}1.462 * * \\
(0.676)\end{array}$ & $\begin{array}{c}0.277 \\
(0.609)\end{array}$ & $\begin{array}{c}1.998^{* * *} \\
(0.712)\end{array}$ & $\begin{array}{l}2.375 \\
(1.752)\end{array}$ & $\begin{array}{l}0.170 \\
(2.149)\end{array}$ \\
\hline \multicolumn{9}{|c|}{$\begin{array}{l}\text { Note: Regressions were run separately for the two types of products (Heavy and upstream). Dependent variable is } 2013 \text { aggregate export } \\
\text { volume. These regressions control for interactions of other factor endowments and factor intensities. Also, we include exporter and product } \\
\text { fixed effects. A positive coefficient of the variable Heavy: } \ln \left(Q_{i}\right) * \text { heavy } \text { implies a comparative advantage in products that are heavy; } \\
\text { whereas, a positive coefficient of Upstreamness: } \ln \left(Q_{i}\right) * \text { upstream } \text { implies a comparative advantage in products that are upstream. The }_{\text {; }} \text { ing } \\
\text { measure of heaviness is the logarithm of weight over value ratio obtained from the UN Comtrade database, 2013. The measure of upstreamness } \\
\text { is the number of stages a product is far from its final demand, as computed in Fally (2012). Robust standard errors in parentheses. }{ }^{* * *} \text { p }<0.01 \text {, } \\
* * \mathrm{p}<0.05, * \mathrm{p}<0.1 \text {. }\end{array}$} \\
\hline
\end{tabular}

As expected, Table A1 shows that countries that have higher quality of transportation infrastructure have a comparative advantage in heavy goods and upstream goods in addition to time sensitive goods (as shown earlier). The results hold for Latin American countries as well. Moreover, we see that the comparative advantage pattern in heavy goods is particularly stronger for primary goods, whereas, comparative advantage pattern in upstream goods is particularly stronger for processed goods in Latin America. This result comes from the differences in product characteristics between primary and processed goods, on average. 
Primary goods are relatively heavier while processed goods are relatively more integrated in the global supply chain.

\begin{tabular}{|c|c|c|c|c|}
\hline Sector & Heavy (in logarithms) & $\begin{array}{l}\text { Change in Export Vol } \\
(\%)\end{array}$ & Upstream & $\begin{array}{c}\text { Change in Export Vol } \\
(\%)\end{array}$ \\
\hline Textile and Wearing Apparel & -1.654 & -17.449 & 1.694 & 11.810 \\
\hline Machinery and Electronics & -0.386 & -4.070 & 1.803 & 12.571 \\
\hline Meat, Dairy and Livestock & 0.069 & 0.728 & 2.213 & 15.427 \\
\hline Vegetables, Fruits and Nuts & 0.285 & 3.005 & 1.491 & 10.396 \\
\hline Light Manufacturing & 0.820 & 8.646 & 2.739 & 19.098 \\
\hline Processed Food & 1.029 & 10.854 & 1.966 & 13.709 \\
\hline Chemicals and Ferrous Metals & 1.056 & 11.139 & 2.578 & 17.972 \\
\hline Extraction & 1.688 & 17.811 & 3.173 & 22.124 \\
\hline Heavy Manufacturing & 1.975 & 20.833 & 2.261 & 15.763 \\
\hline Grains, Fiber and Seeds & 2.190 & 23.108 & 3.408 & 23.761 \\
\hline Other Crops & 2.243 & 23.664 & 2.610 & 18.198 \\
\hline Motor Vehicle and Transport & 4.864 & 51.317 & 1.572 & 10.963 \\
\hline
\end{tabular}

Figure A3. Effect of an $\mathbf{8 . 3 4 \%}$ Improvement in the LPI of an Average Country in LAC

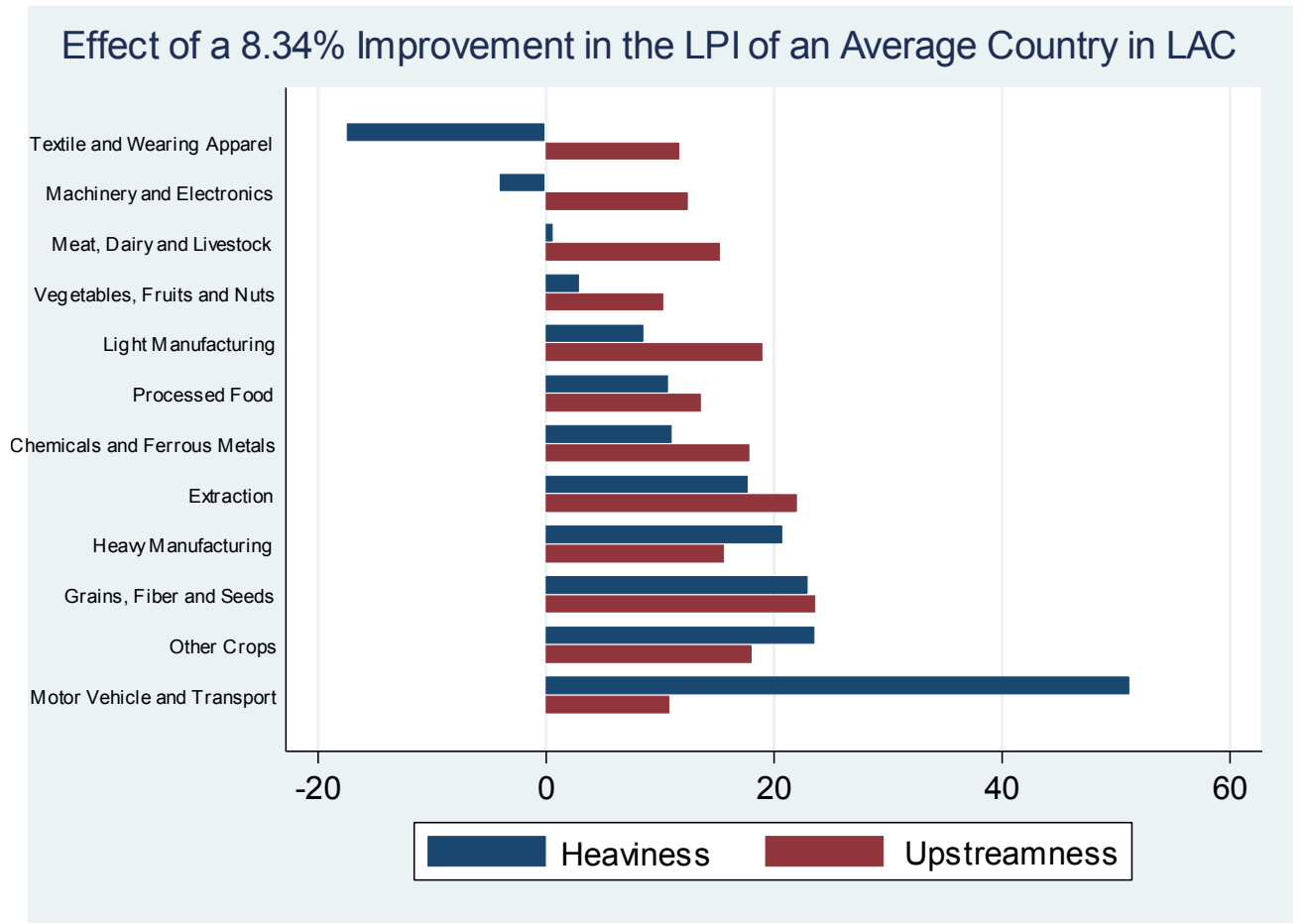

Policy Shock: We introduce $8.34 \%$ improvement in the quality of transportation infrastructure (LPI) of Latin America. This conservative polic shock will increase the 2016 LPI level of Latin America (2.665) to the 2016 LPI level of Middle East and North Africa (2.887), which has th next best level of infrastructure quality after Latin American region. We use the coefficients obtained in Table 3, Latin America (Column 2). 
Figure A4. Correlation Between Logistics Performance Index and Other Measures of Timeliness

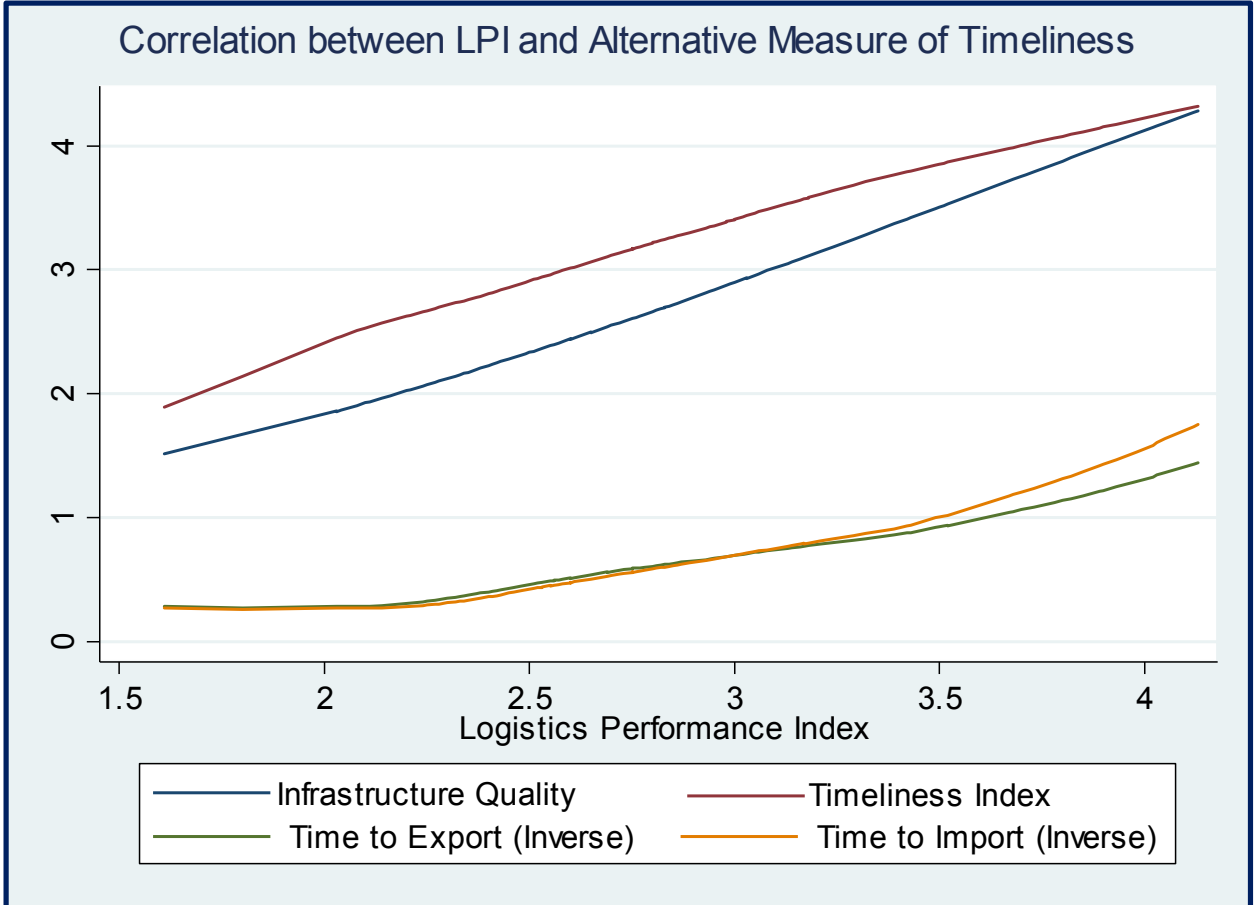

Note: Index on infrastructure quality and timeliness are extracted from the components of the World Bank's Logistics Performance Index Databa (2012). We use the inverse of time to export and time to import data from the World Bank's Doing Business Survey, 2012. This confirms th using LPI as a proxy for transportation infrastructure quality or the ability of a country to transport goods on time in this analysis is reasonable. 


\begin{tabular}{|c|c|c|c|c|c|c|c|c|c|c|c|}
\hline \multicolumn{12}{|c|}{ Table A3. Measure for Factor Intensities Across Product Groups } \\
\hline \multicolumn{6}{|c|}{ Direct Physical Capital Intensity } & \multicolumn{6}{|c|}{ Direct Human Capital Intensity } \\
\hline Goods & \# of HS6 & Mean & Std. Dev. & Min & Max & Goods & \# of HS6 & Mean & Std. Dev. & Min & Max \\
\hline Total & 5,018 & 98076.94 & 47610.01 & 1089.90 & 252358.60 & Total & 5,018 & 8.61 & 1.55 & 2.29 & 12.73 \\
\hline Primary & 561 & 68654.78 & 50349.27 & 1089.90 & 231634.00 & Primary & 561 & 7.89 & 1.88 & 2.82 & 12.23 \\
\hline Processed & 2,639 & 101319.60 & 46640.77 & 1193.89 & 252358.60 & Processed & 2,639 & 8.65 & 1.52 & 2.29 & 12.73 \\
\hline \multicolumn{6}{|c|}{ Indirect Physical Capital Intensity } & \multicolumn{6}{|c|}{ Indirect Human Capital Intensity } \\
\hline Goods & \# of HS6 & Mean & Std. Dev. & Min & Max & Goods & \# of HS6 & Mean & Std. Dev. & Min & $\operatorname{Max}$ \\
\hline Total & 3,491 & 87442.20 & 152306.70 & -253.92 & 664825.90 & Total & 3,491 & 7.13 & 12.15 & -0.04 & 53.26 \\
\hline Primary & 382 & 42529.32 & 49013.94 & 323.40 & 664825.90 & Primary & 382 & 3.96 & 4.16 & 0.03 & 53.26 \\
\hline Processed & 1,830 & 142944.40 & 191158.30 & -253.92 & 664825.90 & Processed & 1,830 & 11.56 & 15.23 & -0.04 & 53.26 \\
\hline \multicolumn{6}{|c|}{ Direct Land Intensity } & \multicolumn{6}{|c|}{ Direct Natural Resource Intensity } \\
\hline Goods & \# of HS6 & Mean & Std. Dev. & Min & Max & Goods & \# of HS6 & Mean & Std. Dev. & Min & Max \\
\hline Total & 5,018 & 0.53 & 0.24 & 0.03 & 2.88 & Total & 5,045 & 13826.66 & 7917.56 & 1500.76 & 89836.93 \\
\hline Primary & 561 & 0.61 & 0.33 & 0.05 & 2.77 & Primary & 578 & 16107.69 & 12056.56 & 1500.76 & 89836.93 \\
\hline Processed & 2,639 & 0.54 & 0.26 & 0.03 & 2.88 & Processed & 2,649 & 14137.83 & 7877.69 & 2264.83 & 79966.70 \\
\hline \multicolumn{6}{|c|}{ Indirect Land Intensity } & \multicolumn{6}{|c|}{ Indirect Natural Resource Intensity } \\
\hline Goods & \# of HS6 & Mean & Std. Dev. & Min & Max & Goods & \# of HS6 & Mean & Std. Dev. & Min & Max \\
\hline Total & 3,491 & 0.42 & 0.70 & 0.00 & 3.09 & Total & 3,491 & 11782.74 & 19377.00 & -71.77 & 84352.54 \\
\hline Primary & 382 & 0.29 & 0.29 & 0.00 & 3.09 & Primary & 382 & 7416.66 & 7440.57 & 58.02 & 84352.54 \\
\hline Processed & 1,830 & 0.67 & 0.88 & 0.00 & 3.09 & Processed & 1,830 & 18947.50 & 24140.44 & -71.77 & 84352.54 \\
\hline
\end{tabular}

